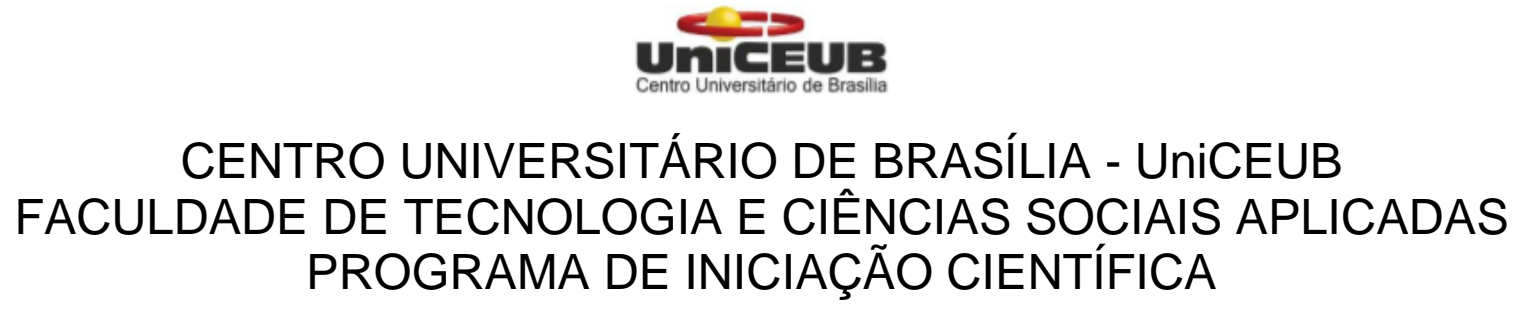

ENTENDIMENTO DA VIDA URBANA POR MEIO DA MORFOLOGIA DOS ESPAÇOS

NOME DA ALUNA

JULIANA LEAL ALVIM

BRASÍLIA-DF

2016 


\section{Unce \\ NOME DA ALUNA \\ JULIANA LEAL ALVIM}

\section{ENTENDIMENTO DA VIDA URBANA POR MEIO DA MORFOLOGIA DOS ESPAÇOS}

Relatório final de pesquisa de Iniciação Científica apresentado à Assessoria de Pós-Graduação e Pesquisa pela Faculdade de Tecnologia e Ciências Sociais Aplicadas - FATECS

Orientação: Prof. ${ }^{a}$ Dra. Ana Paula Borba Gonçalves Barros

\section{BRASÍLIA-DF 2016}




\title{
ENTENDIMENTO DA VIDA URBANA POR MEIO DA MORFOLOGIA DOS ESPAÇOS
}

\author{
Juliana Leal Alvim - UniCEUB, PIC Institucional, aluna bolsista \\ alvim.juju@gmail.com
}

\begin{abstract}
Ana Paula Borba Gonçalves Barros - UniCEUB, professora orientador ana.barros@uniceub.br
\end{abstract}

RESUMO: O objetivo do estudo é analisar qual o impacto da morfologia/sintaxe urbana (em seu aspecto sistêmico) na promoção de viagens a pé em espaços urbanos situados no Distrito Federal. E verificar de que modo os preceitos de Jane Jacobs, Jan Gehl e Bill Hillier, de fato, alimentam a vida no espaço urbano. Sendo assim, e com base no trabalho de Barros (2014), eis que a presente pesquisa pretende verificar se os resultados alcançados para espaços urbanos europeus (mais precisamente em Portugal - Lisboa) se confirmarão em espaços situados no contexto da América Latina, mais especificamente no Distrito Federal (Brasil). Para isso, foram coletados dados em três regiões do DF: Varjão (Malha Orgânica ou Irregular); Taguatinga (Malha Ortogonal ou Regular); e a unidade de vizinhança modelo do Plano Piloto 107/307 e 108/308 sul (Malha Modernista). Esses dados foram tabelados e submetidos à estatísticas básicas entre as variáveis. Utilizou-se o software Depthmap $\AA$ para feitura de mapas axiais e de segmentos dos três estudos de caso supracitados, o que permite o cálculo de um conjunto de variáveis ou índices, a mensurar: conectividade, segregação, integração, etc. A partir daí, foi possível verificar: a importância da diversidade de usos (Jacobs), misturando usos principais em diferentes horários para manter a rotatividade de pessoas no local (que acabam se tornando os olhos da rua). Isso garante maiores segurança, fluxos e valorização econômica do local. Também verificou-se a necessidade de maior conectividade entre os espaços, para que as distâncias percorridas sejam menores (Jacobs) e a importância do número de portas e detalhes na fachada para um fluxo de pessoas ativo e mais convidativo (Gehl). E, por fim, a Teoria da Lógica Social do Espaço, criada por Hillier e Hanson (1984), teve grande relevância para o projeto já que sua criação, amparada pelos pensamentos sistêmico e estruturalista (cf. Derridá, 1971; Foucault, 1971; Hillier et al., 1993; Lefebvre, 1999; Capra, 2003), deriva da preocupação que, segundo Hillier e Hanson (1997), "[...] as teorias [espaciais] tem sido extremamente normativas e pouco analíticas". Então, estes subsídios supracitados tornam-se meios de analisar o impacto da morfologia/sintaxe urbana em seu aspecto sistêmico, permitindo ao pesquisador refletir sobre a cidade de acordo com as articulações urbanas. Assim, foi possível investigar o relacionamento entre o espaço construído - o edifício ou a cidade, grosso modo referido como arquitetura - e a sociedade - vista como um sistema de possibilidades de encontros (Holanda, 2002).

Palavras-chave: Mobilidade urbana. Sintaxe espacial. Pedestres. 


\section{SUMÁRIO}

INTRODUÇÃO

CAPÍTULO 1: REFERENCIAL TEÓRICO 6

1.1. Forma Urbana 6

1.2. Teoria da Sintaxe Espacial 6

1.3. Vida urbana 7

-1.3.1. Jane Jacobs 7

-1.3.2. Jan Gehl 8

CAPÍTULO 2: METODOLOGIA 10

2.1. Caracterização das áreas de estudo 10

-Varjão (malha orgânica) 10

-Taguatinga (malha ortogonal) 10

2.2. Explicação da metodologia 12

-2.2.1. Mapas Axiais 12

-2.2.2. Levantamento de dados 14

CAPÍTULO 3: RESULTADOS 21

3.1. Varjão 21

3.2. Taguatinga 24

3.3. Plano Piloto 29

CONSIDERAÇÕES FINAIS 35

REFERÊNCIAS 36 


\section{INTRODUÇÃO}

A transformação nos espaços urbanos ao longo do tempo, inclusive para expressar um progressivo foco no veículo particular pode ser investigada, de acordo com Medeiros (2013), quanto às diferentes geometrias e topologias urbanas - relações e hierarquias. O que significa explorar a perspectiva do estudo da forma para a compreensão de como as transformações na cidade, inclusive entre as escalas humana e motorizada, afetam/podem afetar o ato de caminhar.

Cabe ressaltar, que o fato da maioria dos planejadores urbanos, arquitetos, urbanistas etc não observarem a forte influência exercida pela forma urbana nos deslocamentos, como atesta Barros (2014), faz com que os espaços sejam pensados, muitas vezes, de forma inadequada para as pessoas, tornando as cidades voltadas aos carros e não às pessoas (Gehl, 2010).

É sob este prisma que este trabalho visa apresentar os resultados preliminares de um estudo realizado em três cidades do Distrito Federal - Varjão, Taguatinga e Plano Piloto (Asa Sul) - com base na metodologia qualitativa utilizada por Barros (2014), de modo a verificar como ocorre o desempenho destas três áreas, com distintas características morfológicas, no que tange a vida nos espaços. 


\section{CAPÍTULO 1: REFERENCIAL TEÓRICO}

\subsection{Forma Urbana}

Para Kostof $(1992,2001)$, há principalmente dois tipos de forma urbana: a irregular/orgânica e a regular/grelha/ortogonal/tabuleiro de xadrez. No entanto, para o autor, as cidades não são compostas de maneira rígida por tais tipos de malha, mas sim pela mistura existente entre os extremos de regularidade e de irregularidade. Dificilmente se conseguiria ter hoje um desenho homogêneo que se distribua por toda a cidade.

Alexander (2006), ao investigar a temática, assume uma diferenciação em formas: (a) naturais - para aquelas malhas cujo surgimento se dá de maneira "natural", "orgânica" (as ditas orgânicas/irregulares) - e (b) artificiais - para as que nascem do papel, por meio dos desenhos de projetistas/planejadores urbanos (usualmente reguladas, sejam em maior ou menor grau - variando do tabuleiro de xadrez perfeito ao traço modernista ou contemporâneo).

A considerar as informações prévias, para pesquisa e tendo em conta os estudos de caso, assumem-se três tipos de malhas: (a) orgânica/irregular, (b) ortogonal/regular/tabuleiro de xadrez, e (c) pósmoderna/contemporânea. As categorias são as mais recorrentes e paradigmáticas na literatura consultada, além de serem compatíveis com os bairros que servirão de estudo de caso.

\subsection{Teoria da Lógica Social do Espaço}

O objetivo principal da Teoria da Lógica Social do Espaço é investigar o relacionamento entre o espaço construído - o edifício ou a cidade, grosso modo referido como arquitetura - e a sociedade - vista como um sistema de possibilidades de encontros (Holanda, 2002).

A SE, por meio de um método e de técnicas, estabelece relações entre categorias em dois âmbitos: (1) a função do espaço, produto das relações intrínsecas âmbito sintático; e (2) o significado do espaço - âmbito semântico - como ocorre a relação entre grupos e indivíduos, clivagens sociais, hierarquias de poder.

A criação da teoria, amparada pelos pensamentos sistêmico e estruturalista (cf. Derridá, 1971; Foucault, 1971; Hillier et al., 1993; Lefebvre, 1999; Capra, 2003), deriva 
da preocupação que, segundo Hillier e Hanson (1997), "[...] as teorias [espaciais] tem sido extremamente normativas e pouco analíticas".

A abordagem contempla técnicas de entendimento e representação do espaço, incluindo a estrutura da malha viária, fornecendo subsídios que permitem ao pesquisador investigar a cidade de acordo com as articulações urbanas.

De acordo com Hillier (2005), existe um grande problema que remanesce nos estudos que se dedicam às cidades, em seus diversos níveis: a cidade é continuamente entendida a partir do aspecto social ou físico, com sociólogos dedicados especialmente à primeira feição e arquitetos/engenheiros à segunda. Parece faltar, portanto, a conexão, e afirma: "historicamente, o objetivo da Sintaxe Espacial foi construir a ponte entre a cidade humana e a cidade física".

Das representações recomendadas pela Teoria da Lógica Social do Espaço para estudos configuracionais (espaços convexos, campos visuais e linhas), duas são de particular interesse para esta pesquisa: campos visuais (mapa de visibilidade ou isovistas) e linhas (mapas axiais e de segmentos).

\subsection{Vida urbana}

\subsubsection{Jane Jacobs}

Jacobs (2001), ainda no início da década de 60, decidiu publicar o registro de suas sensações acerca das cidades dos EUA. $O$ incômodo que sentia baseava-se na necessidade de arquitetos, urbanista e planejadores urbanos terem mais ciência a respeito de que componentes tornavam uma cidade mais viva, o que requeria a compreensão das articulações inerentes ao espaço urbano. Jacobs (2001) formulou quatro condições que acreditava serem essenciais para que houvesse diversidade 'exuberante' nas ruas em espaços públicos urbanos, o que favorecia seu uso, portanto gerando fluxos e segurança.

(a) Necessidade de usos principais combinados - diversidade de usos

(b) Necessidade de quadras curtas - maior conectividade entre os espaços

(c) Necessidade de prédios antigos - idades variadas dos prédios

(d) Necessidade de concentração - densidade urbana significativa. 
Ressalta-se, entretanto, que para este trabalho, devido o reduzido tempo e a dimensão da pesquisa, apenas a 1ํㅡㄹ condição (usos principais combinados) será estudada.

$\mathrm{Na}$ perspectiva de Jacobs (2001), o que parece crucial para uma melhor dinâmica e vida urbana é o fator "diversidade". Destacou como critérios prioritários: diversidade de usos e tipos edilícios (em oposição à padronização), presença de quadras curtas (o que significa uma relação mais alimentada de vias articulando as quadras), existência de edifícios de variadas idades, densidade construída e populacional (os pólos máximo e mínimo são prejudiciais). A mistura de pessoas, usos e edifícios (dada a interdependência entre estas três instâncias), asseguraria um espaço mais rico, alimentado e, portanto seguro. Seriam áreas mais convidativas aos deslocamentos, especialmente para aqueles realizados a pé, no âmbito da caminhabilidade, em que a interação indivíduo/meio é mais franca, pois não há o invólucro do carro a criar uma separação.

\subsubsection{Jan Gehl}

Gehl (2010) caminha na mesma direção de Jacobs, mas acrescenta ainda a precaução que deve existir com o tratamento do térreo dos edifícios (rés-do-chão) chamados de espaços de transição, por estabelecer a ligação entre o privado com o público - para a promoção de uma cidade ao nível dos olhos, o que favoreceria simultaneamente a interação e a segurança. Portanto, ao se estudarem espaços para pedestres, nos quais os olhos são o sentido mais utilizado na percepção do espaço (além dos pés, é claro), o nível da rua deve merecer especial atenção.

Neste caso, atenção deve existe com a alimentação da rua, o que se vincula à redução do caráter "cego" de alguns trechos de via, em que praticamente inexistem portas ou janelas. Gehl (2010), com base nisso, adotou classificação de 5 níveis no que se refere à percepção do trecho da rua:

(a) Ativo - 15 a 20 portas a cada $100 \mathrm{~m}$

(b) Convidativo - 10 a 14 portas a cada $100 \mathrm{~m}$

(c) Misto -6 a 9 portas a cada $100 \mathrm{~m}$

(d) Monótono - 2 a 5 portas a cada $100 \mathrm{~m}$

(e) Inativo -0 a 1 portas a cada $100 \mathrm{~m}$ 
As características destes níveis estão diretamente relacionados com a morfologia dos espaços, portanto, um bom indicador de vivacidade dos espaços públicos urbanos, a incluir aquelas que acolhem os deslocamentos. 


\section{CAPÍTULO 2: METODOLOGIA}

\subsection{Caracterização das áreas de estudo}

Para esta pesquisa foram levantadas três áreas de estudo no DF com tecidos urbanos diferentes entre si. Dessa forma, será possível perceber as diferenças de fluxos existentes em cada uma destas regiões.

\section{- Varjão (malha orgânica)}

O Varjão é uma RA (Região Administrativa) composta por assentamentos e diversos condomínios antes pertencentes a Sobradinho. Ou seja, não houve um planejamento prévio e os moradores foram se apropriando livremente do espaço constituindo uma malha orgânica, natural. Segundo a Pesquisa Distrital por Amostra de Domicílios (PDAD) de 2015, sua população urbana estimada estava em 9.215 habitantes.
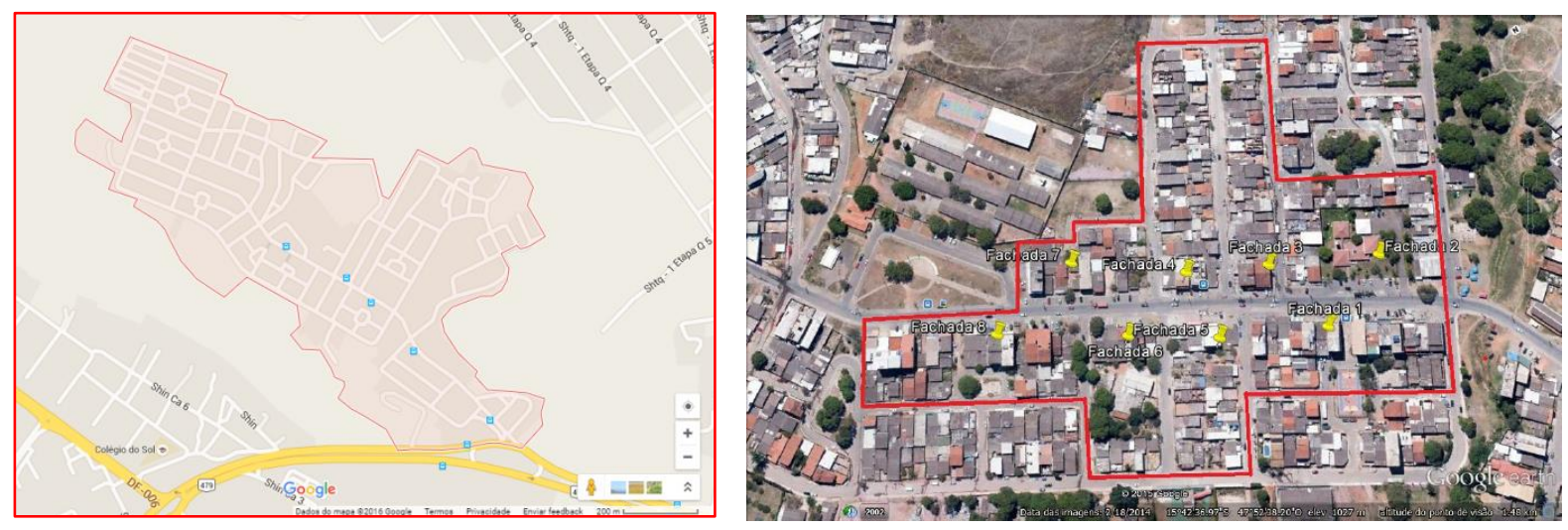

Figura 2.1.A (Perímetro RA: Varjão) Figura 2.1.B (Perímetro área de estudo no Varjão)

\section{- Taguatinga (malha ortogonal)}

Taguatinga foi fundada em 1958 como um povoamento; e já continha residências, hospitais, escolas e estabelecimentos comerciais em funcionamento. Nessa época, chegavam os primeiros habitantes, majoritariamente para a construção de Brasília. Mas somente em 1970 foi considerada uma cidade, sendo a primeira cidade satélite do DF e um importante polo comercial. Sua ocupação deu-se de modo ortogonal, regular. E, segundo o anuário do DF, sua população é estimada em 221 mil habitantes. 


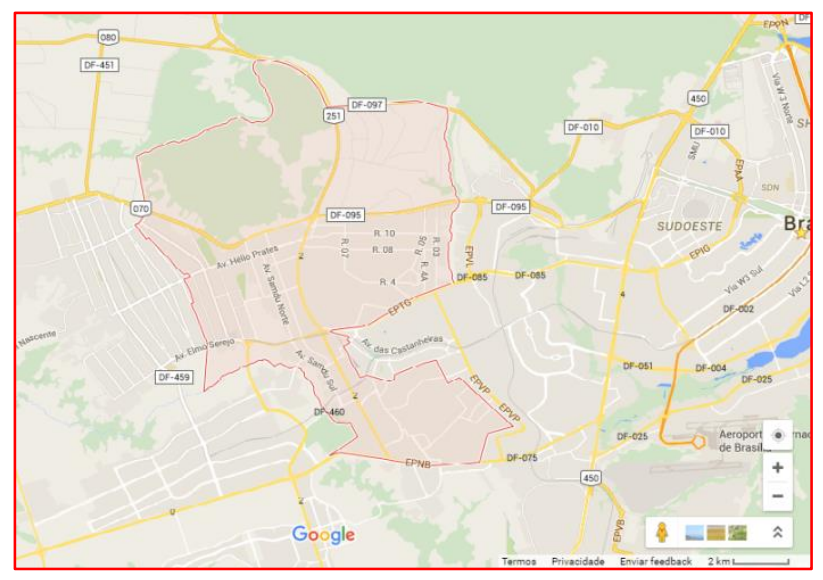

Figura 2.1.C (Perímetro RA: Taguatinga) Taguatinga)

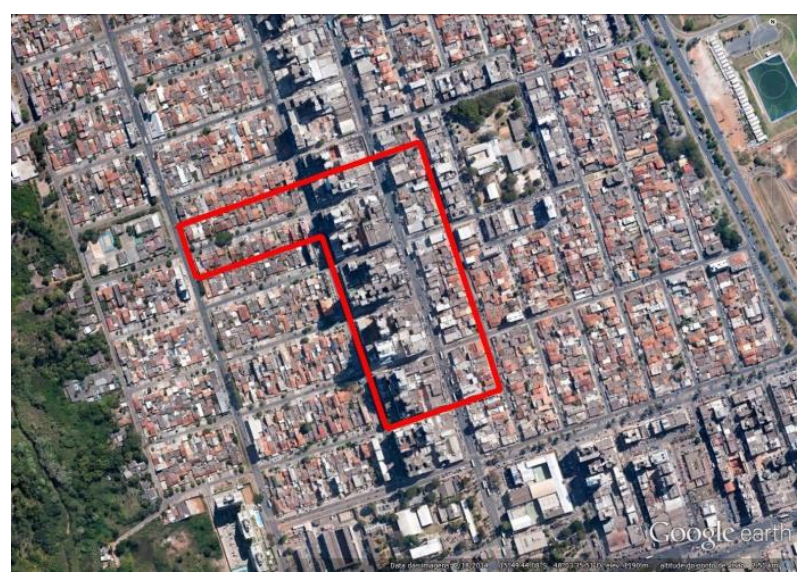

Figura 2.1.D (Perímetro área de estudo em

\section{- Plano Piloto (malha modernista)}

O Plano Piloto de Brasília foi criado pelo arquiteto e urbanista Lúcio Costa e foi inaugurado em 1960. Ele é cortado pelo Eixo Monumental, onde estão os principais monumentos e edifícios político-administrativos da cidade. $\mathrm{E}$ por um grande eixo rodoviário: o Eixão, onde abaixo estão dispostas as quadras 200, 400, 600 e 800; e acima, as quadras 100, 300, 500, 700 e 900. Esta RA é claramente dividida em setores, delimitados por funções e, por isso, apresenta zonas residenciais e comerciais, por exemplo, bem separadas. Sua malha, portanto, é tipicamente modernista. Segundo o anuário do DF, sua população urbana é estimada em 200 mil habitantes.

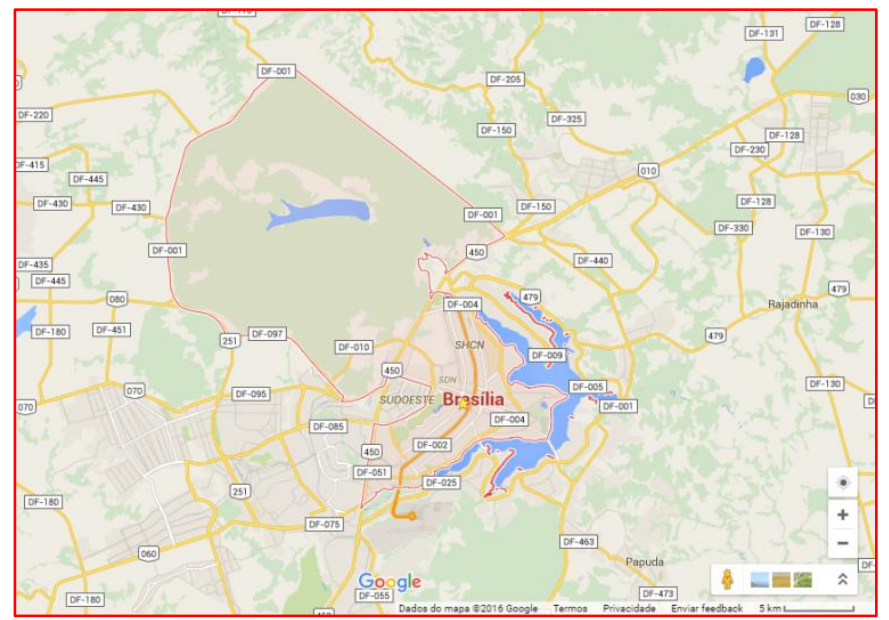

Figura 2.1.E (Perímetro RA: Plano Piloto) no Plano Piloto)

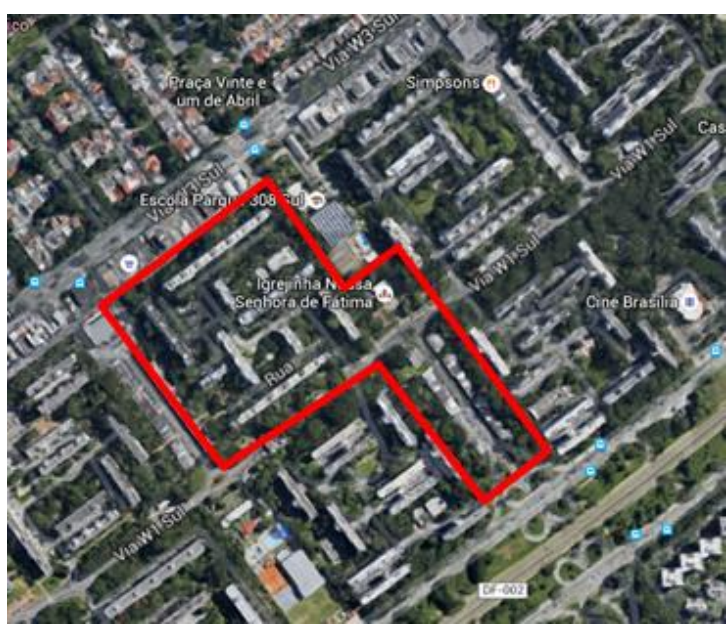

Figura 2.1.F (Perímetro área de estudo 


\subsection{Explicação da metodologia}

De modo a entender os processo de utilização dos espaços, faz-se necessário compreender a maneira como os espaços se organizam no tangente às suas morfologias. Para isso, conforme explicado no item anterior, fez-se uso dos mapas axiais.

\subsubsection{Mapas Axiais}

A representação linear utilizada na pesquisa - o Mapa Axial - é obtida traçando sobre a malha viária (a partir da base cartográfica disponível) o menor número possível de linhas retas dentro do eixo carroçável (Figura 2.2.1 A, B e C).
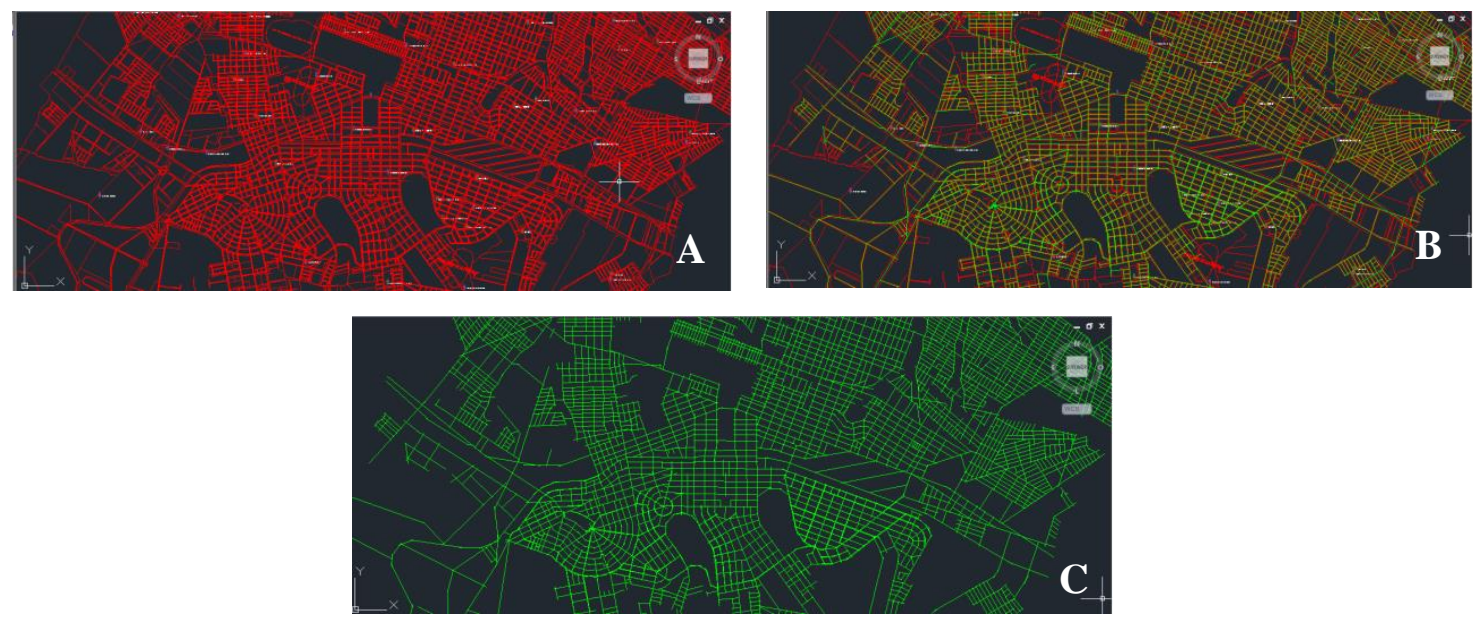

Figura 2.2.1 - (A) Base cartográfica da cidade de Maringá - PR (Parcial), (B) camada de eixos oriundos da representação linear (em verde) e (C) representação linear da cidade de Maringá - PR (parcial) - no software Autocad®

Fonte: Prefeitura Municipal de Maringá - PR. Crédito: Késsio Furquim apud Barros (2014).

Após o processamento, realizado no software Depthmap $\AA$, obtem-se uma matriz de interseções, a partir da qual são calculados valores representativos de suas interrelações axiais (Hillier e Hanson, 1984; Hillier, 1996; Holanda, 2002; Medeiros, 2013).

Esse procedimento resulta do cálculo da matriz de interseções total do sistema, na qual são consideradas todas as conexões a partir de todos os eixos. Obtém-se, assim, um valor denominado $\mathrm{Rn}$, em que $\mathrm{R}$ representa o raio (quantos eixos se quer considerar a partir de um outro qualquer) e n o número ilimitado de conexões. Aos 
valores obtidos a partir da representação e quantificação do espaço urbano no nível desejado - que traduzem o potencial de atração de fluxos e movimento de determinado eixo ante o complexo urbano dá-se o nome de valor ou potencial de integração, acessibilidade ou permeabilidade.

Esses valores podem ser representados numericamente ou numa escala cromática com gradação indo do vermelho, passando pelo laranja e verde até chegar ao azul - nos quais os eixos com maior valor de integração tendem a vermelho, e os de menor, a azul.

Eixos mais integrados são aqueles mais permeáveis e acessíveis no espaço urbano, de onde mais facilmente se alcançam os demais. Implicam, em média, os caminhos topologicamente mais curtos para serem atingidos a partir de qualquer eixo do sistema. Eixos mais integrados tendem a assumir uma posição de controle, uma vez que podem se conectar a um maior número de eixos e hierarquicamente apresentam um potencial de integração superior.

Isso permite consequentemente a visualização de uma malha viária em gradações de potenciais de fluxos e movimentos, isto é, de integração. Torna-se perceptível a definição de áreas com predominância de eixos de grande potencial de movimento em oposição àquelas áreas periféricas de menor fluxo.

A representação linear investigada na presente pesquisa é o Mapa Axial, que compreende a representação linear processada (Figuras 2.2.1 D e E), resultando num mapa de eixos que revela, por exemplo, a acessibilidade da trama existente por meio de uma escala cromática, de tons de cinza ou espessura de linha (caso a variável selecionada contemple o valor de integração). Esta acessibilidade pode ou não corresponder aos fluxos reais, tendo em vista a convergência de diferentes variáveis (incluindo tipos de pavimentação, existência de Polos Geradores de Viagem, etc.), por isso se diz que um mapa axial ilustra a potencialidade de geração de movimento, e não necessariamente o movimento real. 

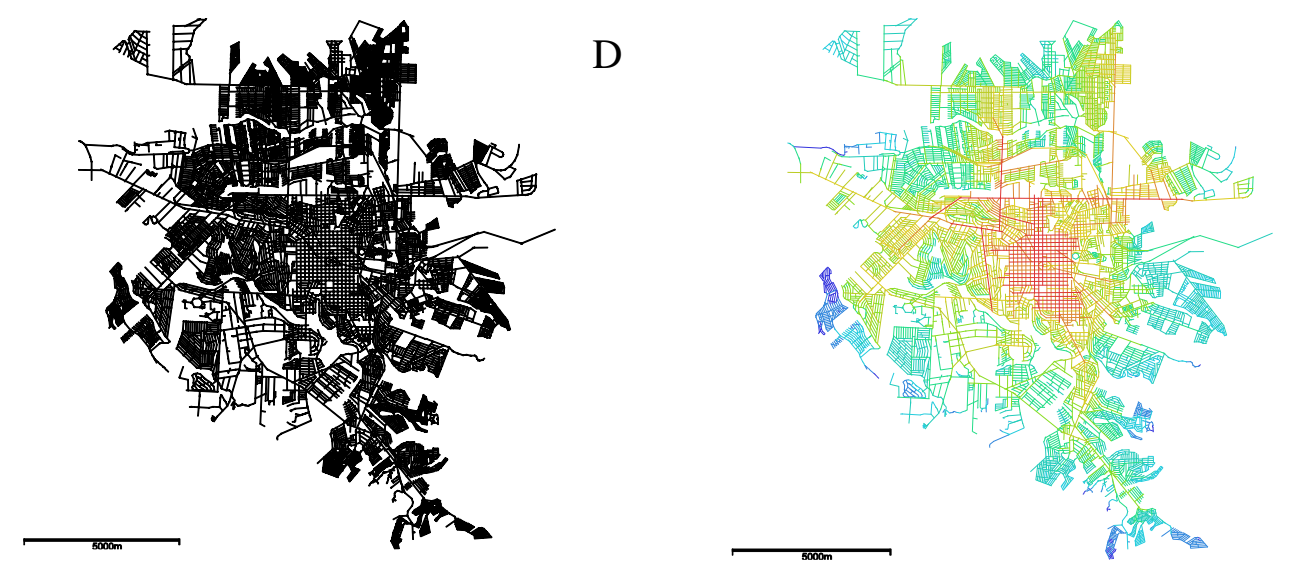

$\mathrm{E}$

Figura 2.2.1 - (D) Representação Linear da cidade de Maringá - PR e (E) Mapa Axial da cidade de Maringá - PR (variável integração Rn)

Crédito: Késsio Furquim apud Barros (2014).

\subsubsection{Levantamento de dados}

\section{- Uso do solo}

O levantamento de uso do solo consiste em abordar a variedade de usos e funções do espaço nas áreas de estudos, a fim de verificar de que maneira as distintas formas urbanas se coportam em termos de vida urbana. Tal diversidade é fator preponderante nos fluxos e movimentação de pessoas nos espaços, tal como preconizado desde a década de 60 por Jacobs (2000), e ratificado por Gehl (2010) anos depois.

O levantamento do uso do solo nas três áreas de estudo foi realizado adequando-se às peculiaridades de cada espaço. Inicialmente, para as três áreas de estudo, foram escolhidos dois tipos viários: (a) com predominância de comércios/serviços e (b) com predominância de residências - para o caso da Asa Sul, por sua rígida setorização, na área residencial foi exclusiva, ou seja, não há qualquer tipo de comércio ou serviço.

De modo a se adequar com a contagem de portas (explicada no subitem a seguir), o levantamento de uso do solo foi realizado em conformidade com a análise de Gehl (2010), na qual utiliza o número de portas por 100 metros. Assim sendo, procedeu-se da seguinte maneira: 
(a) no Varjão (Figura 2.2.2 A), o tamanho utilizado foi de 400 metros exatos (4 quarteirões de 100 metros e 8 fachadas - Figura 2.2.2.B) na via de predominância comercial e 100 metros para a via de predominância residencial;

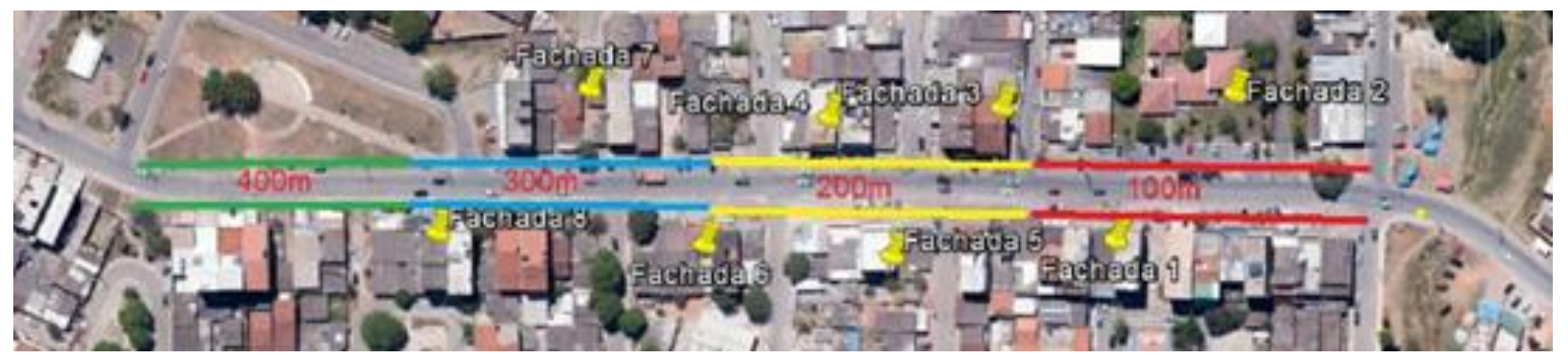

Figura 2.2.2.A - 400 metros de levantamento na avenida com predominância de comércios do Varjão.

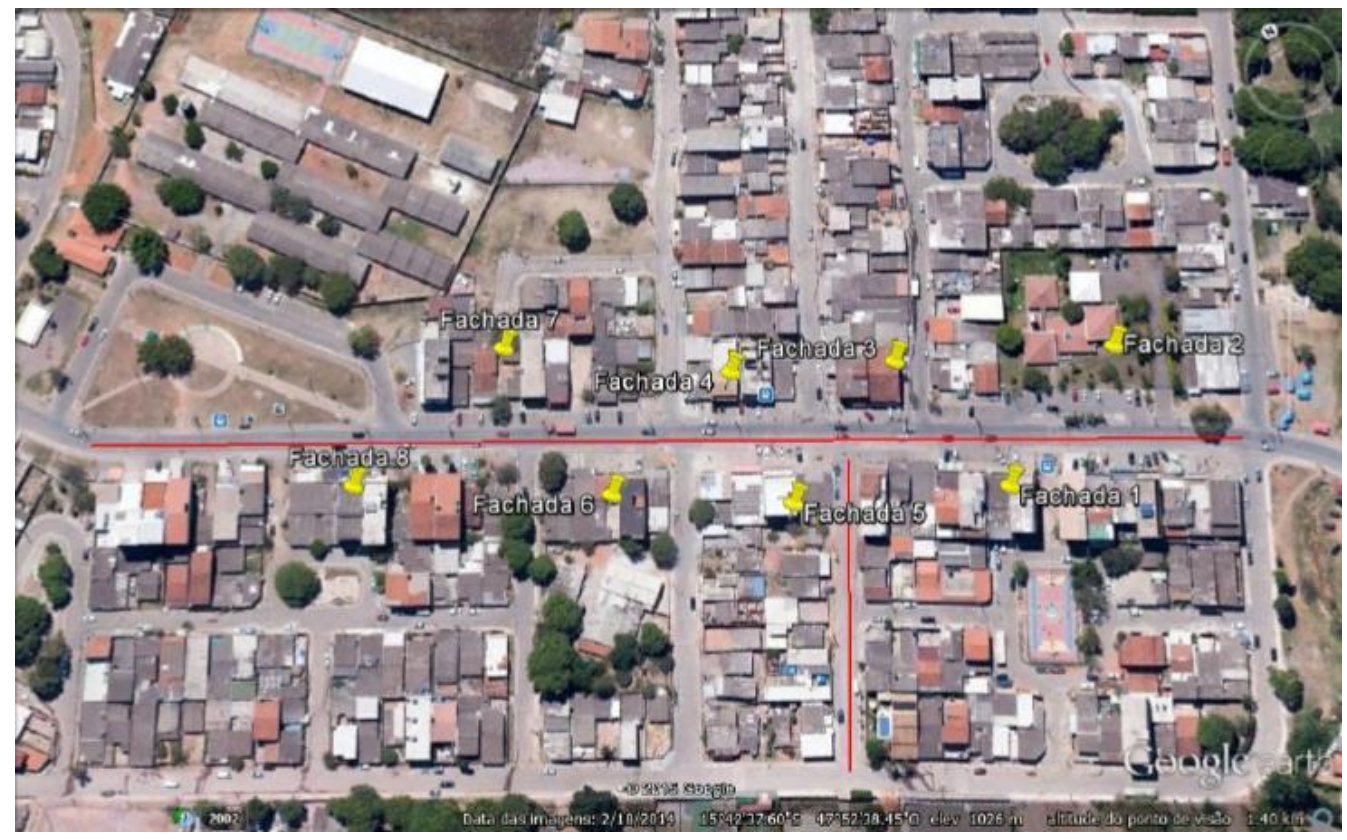

Figura 2.2.2 .B - Fachadas analisadas na avenida comercial (Fachadas 1, 2, 3, 4, 6, 7 e 8) e residencial (Fachada 5) no Varjão.

(b) em Taguatinga (Figura 2.2.2 C), a dimensão foi de 380 metros para a via de predominância comercial e de 330 metros para a de predominância residencial $(110 \mathrm{~m}$ para a transição entre a essencialmente comercial e a essencialmente residencial, e 220 para a essencialmente residencial); e 


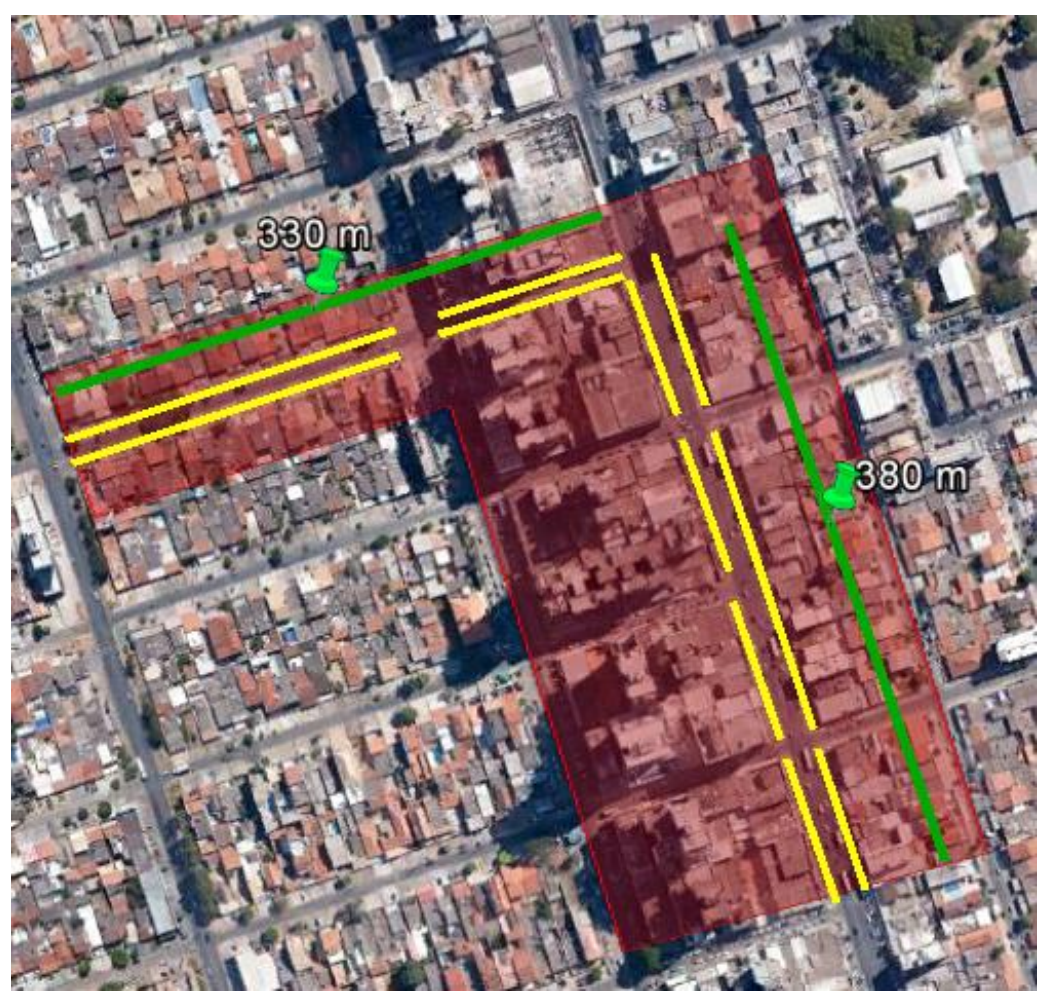

Figura 2.2.2.C - 380 metros de levantamento na rua com predominância de comércios e 330 metros na rua com predominância de residências.

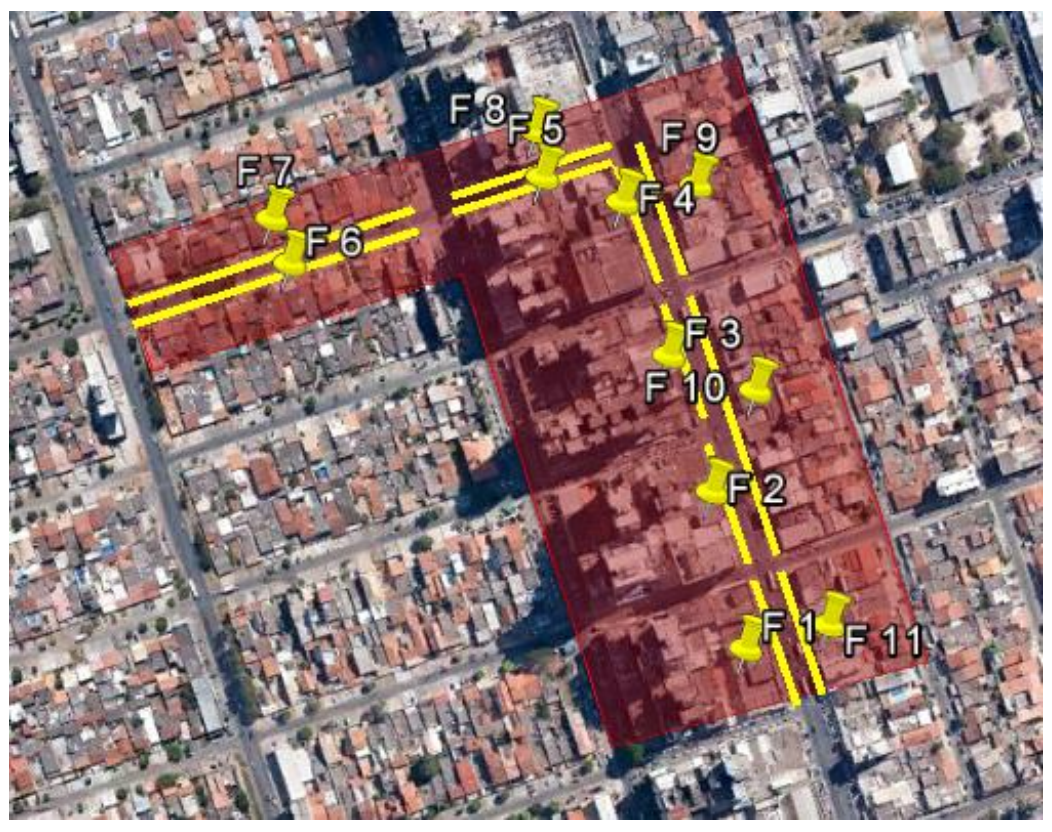

Figura 2.2.2.D - Fachadas analisadas na via comercial (Fachadas 1, 2, 3, 4, 9, 10 e 11) e residencial (Fachadas 5, 6, 7 e 8). 
(c) na Asa Sul, fez-se o levantamento dos 200 metros totais do comprimento da via comercial (SCLS 107/108 - Figura 2.2.2.E) e em toda a superquadra da 308 sul (residencial).

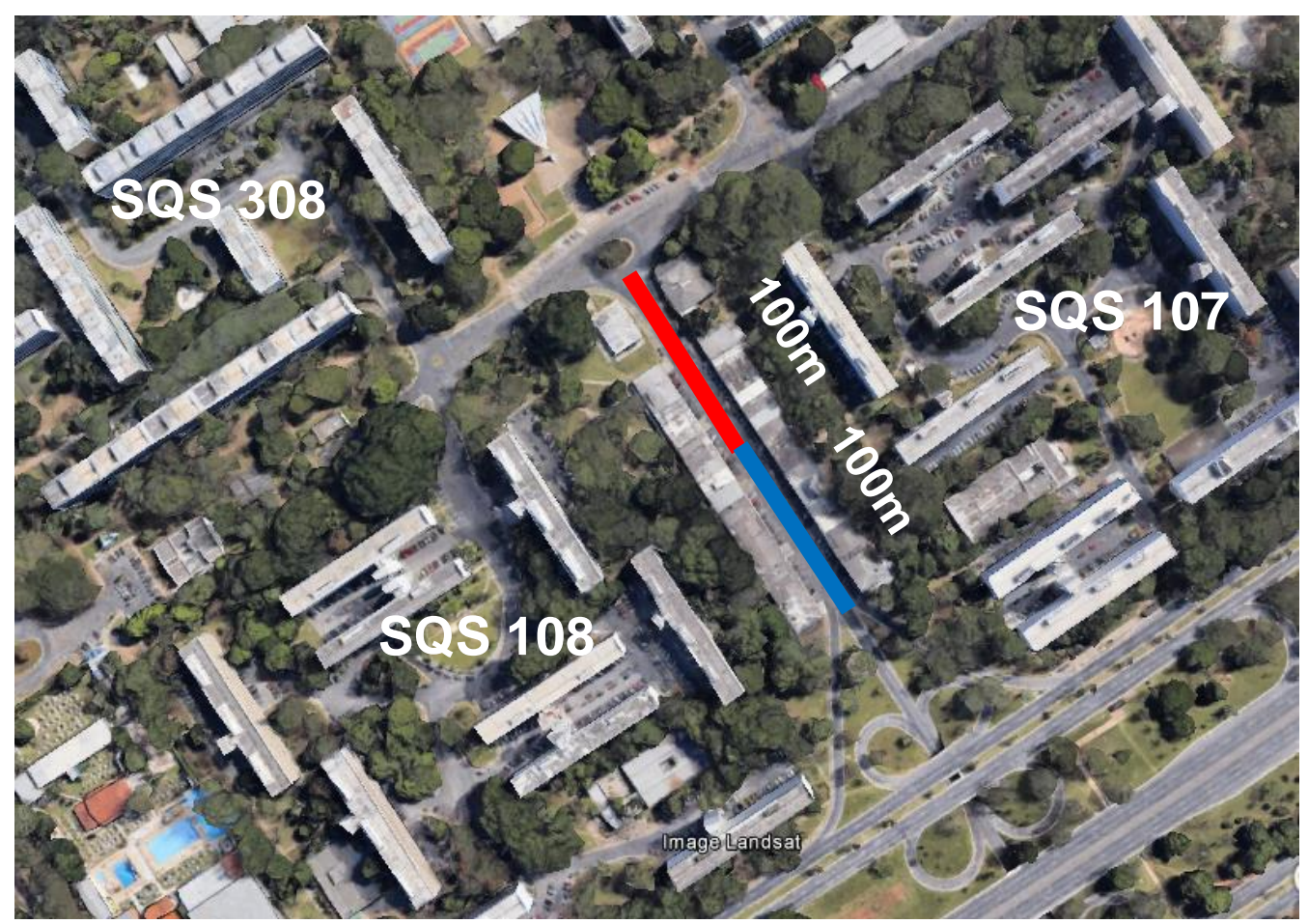

Figura 2.2.2.E - Fachadas analisadas nas vias comercial (Fachadas 1, 2, 3, 4, 9, 10 e 11) e residencial (Fachadas 5, 6, 7 e 8).

\section{- Número de portas}

A contagem do número de portas foi realizada de modo a se aproximar ao máximo nos 100 metros de fachadas para as ruas (mas tendo em conta as especificidades dos três espaços em estudo), para em seguida enquadrar os resultados encontrados nas categorias descritas no subitem 1.3.2, uma vez que Gehl (2010) relaciona a potencialidade de haver fluxos de pessoas a medida que a quantidade de portas (a cada 100 metros) aumenta e vice-versa. 
Reitera-se, portanto, que este levantamento foi compatiilizado com o de uso do solo, por isso, deve-se ter em conta as mesmas figuras do subitem anterior (uso do solo).

\section{- Contagem de pedestres e veículos}

O objetivo da contagem de pedestres e veículos é ratificar (ou não) os pressupostos dos autores - Jacobs, Gehl e Hillier e Hanson - acima mencionados.

Para a contagem de pedestres e veículos, tomou-se por base a tese de Barros (2014), que adequou-se às contagens de portas, e por isso, utilizou o ponto médio também a cada 100m (para o caso do Varjão - Figura 2.2.2.F) (ou próximo dos 100 Figura 2.2.2.C), ou seja, aos $50 \mathrm{~m}$ (ou um pouco mais, a depender do caso), e chamouse de ponto de contagem.

A contagem teve como ponto médio uma linha imaginária traçada de uma calçada a outra, cuja duração foi de 2'30" (dois minutos e meio).

Ressalta-se que em casos de vias com fluxo mais intenso, a contagem para pedestres e veículos foi realizada separadamente e em casos de vias com menor fluxo a contagem foi conjunta (Cf. Barros, 2014) - ocorrendo apenas no caso de Taguatinga (Avenida Comercial vs rua local).

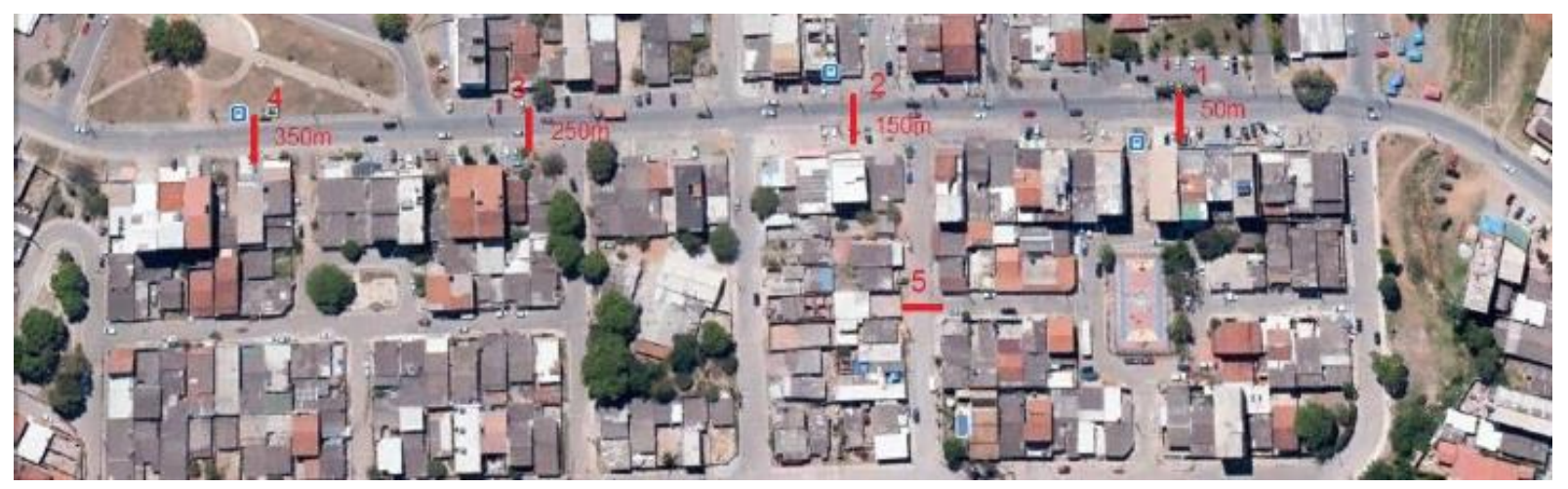

Figura 2.2.2. F - Pontos de contagem de pedestres e veículos no Varjão pontos 1, 2, 3 e 4 na via essencialmente comercial e ponto 5 na via essencialmente residencial. 


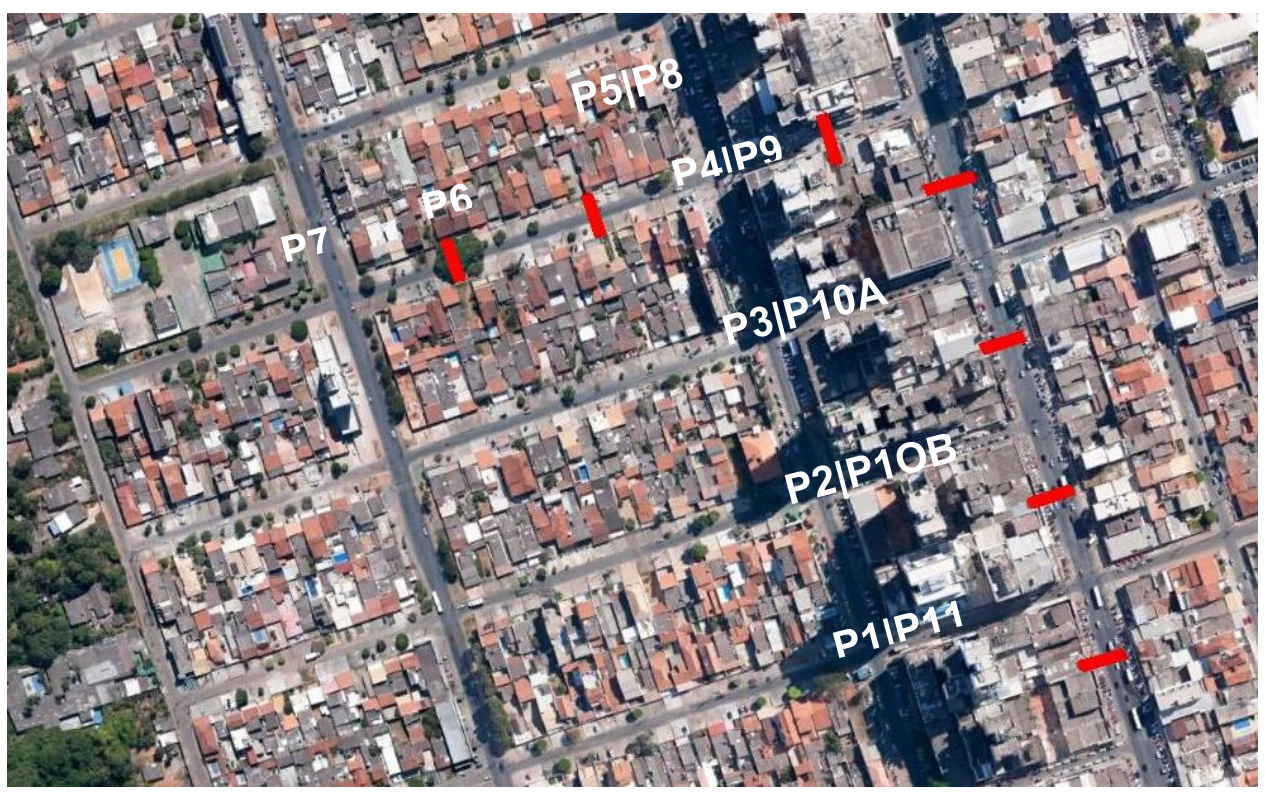

Figura 3.2.2.G (Pontos de contagem de pedestres e veículos em Taguatinga)

No caso da zona residencial da área de estudo do Plano Piloto, a SQS 308, o processo foi um pouco diferente devido a rígida setorização da malha modernista. $O$ procedimento foi contornar (pela calçada) o quadrilátero que delimita os blocos. Devido haver várias ramificações (de caminhos pedonais) num só traçado, um ponto foi subdividido em sentido horário (começando pela esquerda) em A, B, C (conforme apresentado na Figura 2.2.2.H) e assim sucessivamente, de acordo com a quantidade de ramos existentes no ponto. $\mathrm{E}$ ali foram contabilizadas as pessoas que cruzavam a linha imaginária em cada subdivisão de ponto de contagem, ou seja, onde havia a ramificação (Cf. Barros, 2014).

A figura Figura 2.2.2.I mostra a localização dos pontos de contagem das comercias da 107 e 108 Sul. O início das contagens foi feita na 107 e terminou na 108, contornando o local na ordem correspondente aos pontos 1 e 6 , tendo os demais pontos como intermediários e sequanciais. 


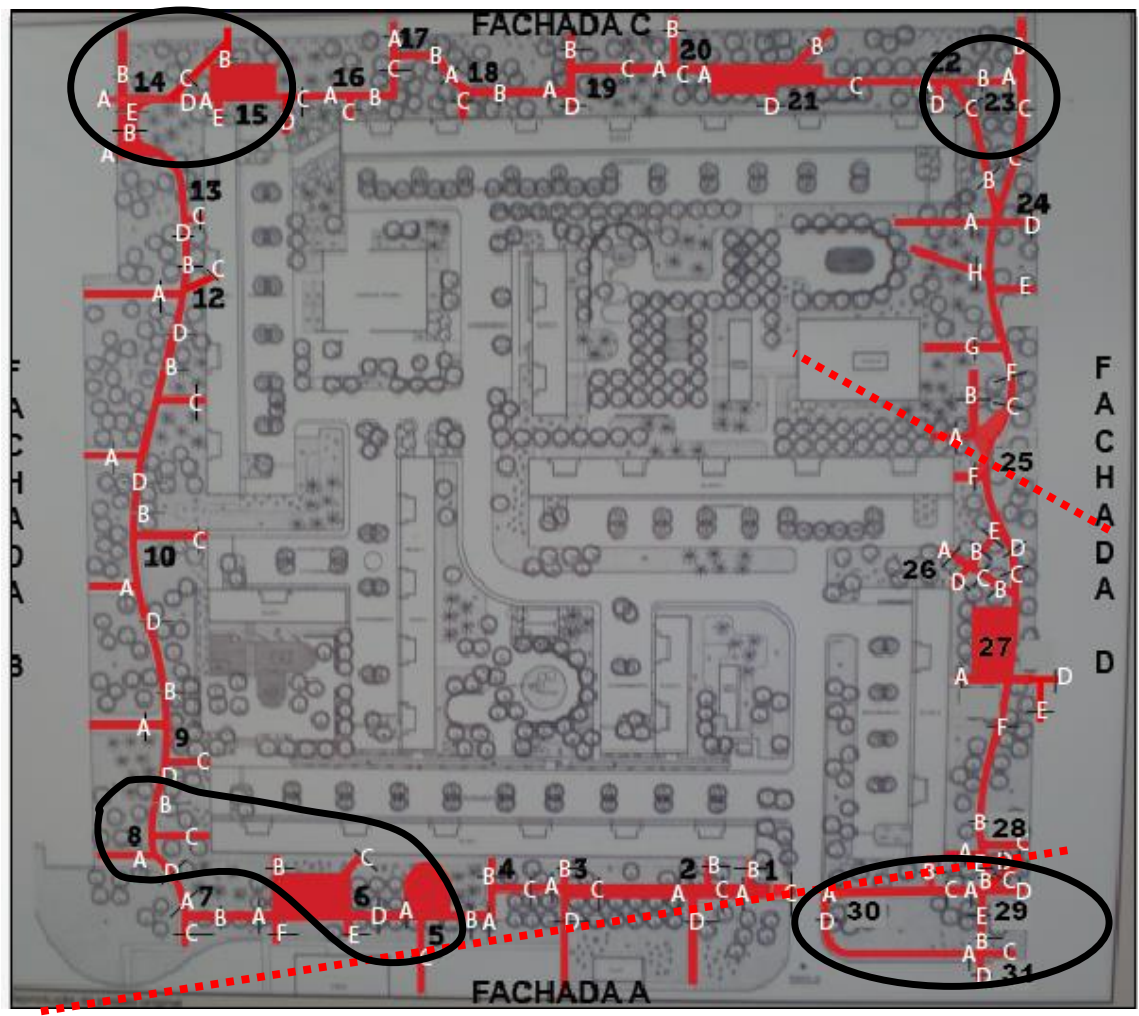

Figura 2.2.2.H - Pontos de contagem de pedestres na residencial da SQS 308.

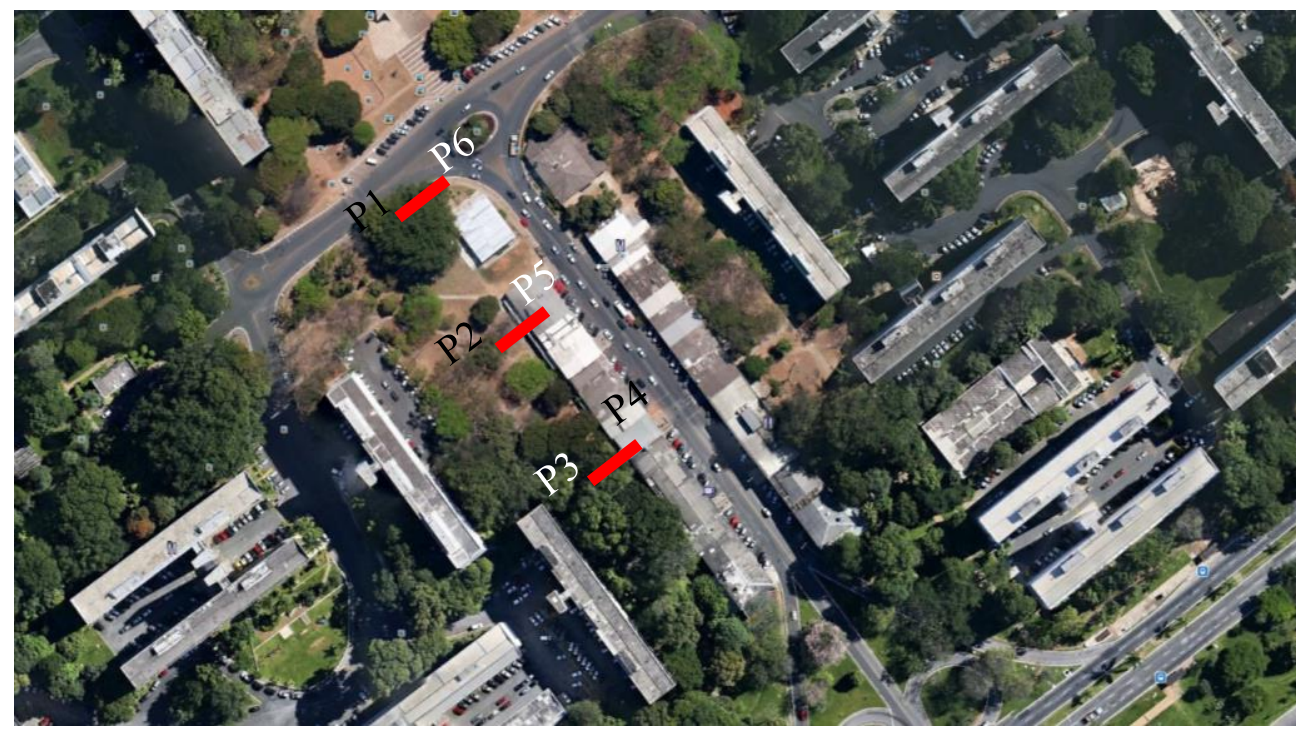

Figura 2.2.2.I -Pontos de contagem de pedestres e veículos na 107/108 Sul. 


\section{CAPÍTULO 3: RESULTADOS}

\subsection{Varjão}

\subsubsection{Mapa Axial}

Tendo em conta a implantação do Varjão - assentamento urbano surgido a partir de invasões de famílias de poder aquisitivo considerado baixo, e somente após certo tempo houve a conformação das ruas com pavimentação e demais inserções infraestruturais - verifica-se que haver uma hierarquia claramente definida a partir do potencial de movimento presente na área. Em outras palavras, a via mais integrada (aquela onde foi realizado o levantamento) é a que assume o controle do espaço, apresentando o maior índice de integração (via em vermelho), caracterizada por apresentar um maior potencial de movimento quer seja de pessoas, quer de veículos (Figura 3.1.1). E o contrário também é verdadeiro, ou seja, as vias em azul, apresentam menor potencial de agregar pessoas.

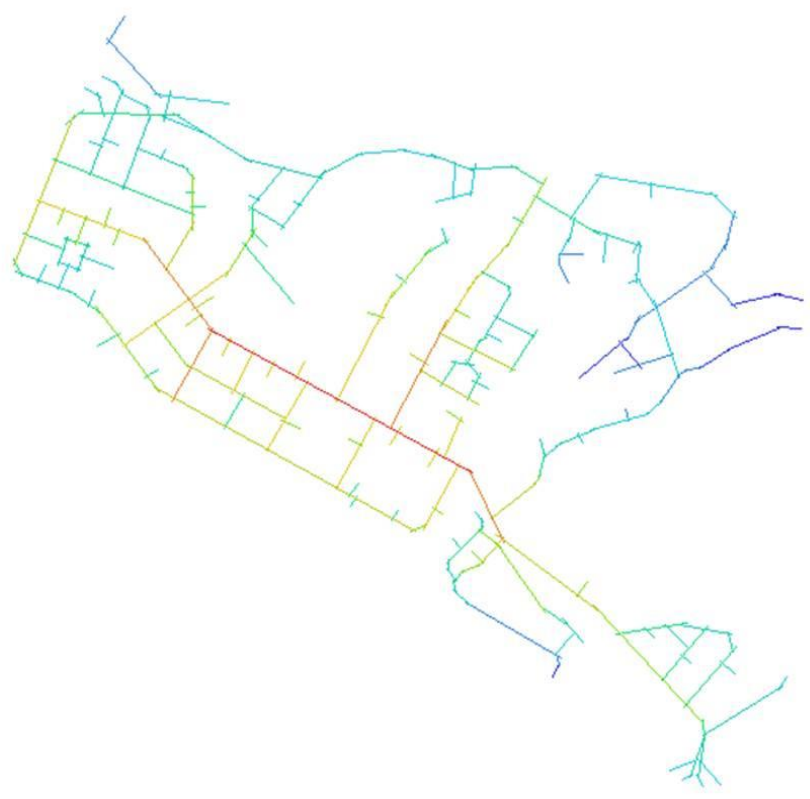

Figura 3.1.1 - Mapa Axial do Varjão

\subsubsection{Uso do solo}


O levantamento realizado na área permitiu atestar a grande variedade de usos combinados existentes no local (Tabela 3.1.2), havendo desde comércios de usos diários, como farmácias e supermercados, até empreendimentos de usos esporádicos, como lojas de roupas e distribuidoras de bebidas. Ademais, a presença de bares e restaurantes, cujo tempo de permanência no espaço aumenta de forma significativa, gerando, portanto, a atração de pessoas para o espaço público por mais tempo, conforme sugeres Jacobs (2000) e Gehl (2010).

Tabela 3.1.2 - Uso do solo

\begin{tabular}{|c|c|c|}
\hline \multicolumn{3}{|c|}{ LEVANTAMENTO DE USO DE SOLO - VARJÃO } \\
\hline Fachada 1 & Fachada 4 & Cont. Fachada 7 \\
\hline Restaurante & Lotérica & Residência \\
\hline Mercado & Utilidades para o lar & Lanchonete e roupas \\
\hline Peixaria & Armazém & Lote vazio \\
\hline Loja vazia & Drogaria e dentista & Loja fechada \\
\hline Panificadora & Boutique & Mototáxi \\
\hline Dentista & Fachada 5 & Fachada 8 \\
\hline Drogaria & Loja de móveis & Barraco \\
\hline Loja de roupas & Restaurante & Residência \\
\hline Lan House & Distribuidora de bebidas & Supermercado \\
\hline Loja de roupas & Loja de eletrônicos & Loja de cosméticos \\
\hline Supermercado & Loja de roupas & Igreja Evangélica \\
\hline Administração do Varjão & BRB Conveniência & Igreja Evangélica \\
\hline Bar & Fachada 6 & Restaurante \\
\hline Bar & Barbearia & Loja fechada \\
\hline Bar & Bar & Residência \\
\hline Fachada 2 & Loja de roupas & Supermercado \\
\hline Loja de móveis & Ótica & Padaria e Dentista \\
\hline Bar & Loja fechada & Igreja Evangélica \\
\hline Loja de calçados & Loja fechada & Papelaria \\
\hline Centro de saúde & Lanchonete & Lote vazio \\
\hline Serralheria & Fachada 7 & Igreja Evangélica \\
\hline Fachada 3 & Papelaria e armarinho & Igreja Evangélica \\
\hline Armarinho & Loja de Bicicletas & Serralheria \\
\hline Materiais de construção & Salão de beleza e papelaria & \\
\hline
\end{tabular}




\begin{tabular}{|l|}
\hline \multicolumn{1}{c|}{ CONTINUAÇÃO: } \\
LEVANT AMENTO DE \\
USO DE SOLO - VARJÃO \\
\hline \multicolumn{1}{|c|}{ Via transversal } \\
\hline 1 Residência \\
\hline Salão de beleza \\
\hline 4 Residências \\
\hline Igreja evangélica \\
\hline Residência \\
\hline Oficina mecânica \\
\hline Residência \\
\hline Prédio em construção \\
\hline
\end{tabular}

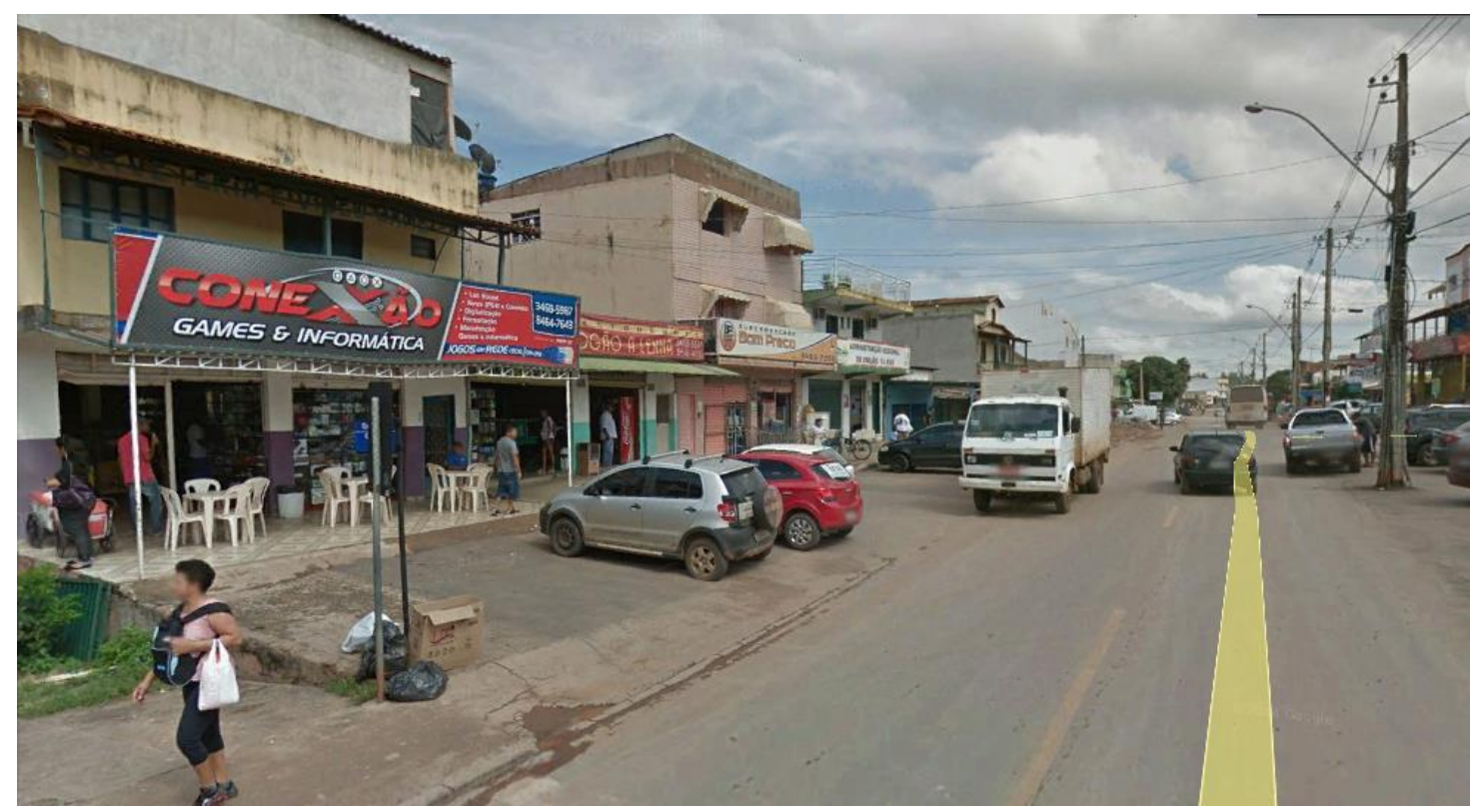

Figura 3.1.2 A - Imagem da via principal do Varjão.

Fonte: Google Earth (2016).

\subsubsection{Número de portas}

Segundo Gehl (2010), a quantidade de portas existentes na área também é fator preponderante para atrair pedestres, bem como a quantidade de detalhes nas fachadas. Conforme apresentado na Tabela 3.1.3, verificou-se que nos primeiros 300m estudados a relação entre o comprimento da fachada e quantidade de portas pode ser classificada como "ativa", de acordo com Gehl (2010). Decaindo apenas para 
"convidativa" nos $200 \mathrm{~m}$ seguintes, mesmo sendo o último trecho residencial, o que, segundo o autor, apresenta um bom indicador de vivacidade neste espaço urbano.

\begin{tabular}{|c|c|}
\hline \multicolumn{2}{|c|}{$\begin{array}{c}\text { CONTAGEM No DE PORTAS - } \\
\text { VARJÃO }\end{array}$} \\
\hline Local & Quantidade \\
\hline $100 \mathrm{~m}$ & 40 \\
\hline $200 \mathrm{~m}$ & 36 \\
\hline $300 \mathrm{~m}$ & 37 \\
\hline $400 \mathrm{~m}$ & 14 \\
\hline$+100 \mathrm{~m}$ (Residencial) & 12 \\
\hline TOTAL & 139 \\
\hline
\end{tabular}

\subsubsection{Contagem de pedestres e veículos}

Verificou-se que, de acordo com as contagens realizadas, o número de pedestres em todos os pontos (Tabela 3.1.4), inclusive aquele situado na via local (ponto 5), foi muito superior ao número de veículos. Isso confirma as premissas de que a diversidade de usos (Jacobs, 2000) e o número de portas (Gehl, 2010) estimulam o uso dos espaços pelas pessoas, bem como, atestam que a depender de como o espaço esteja configurado (Hillier e Hanson, 1984) apresentam mais vida e segurança.

Tabela 3.1.4 - Contagem de pedestres e veículos

\begin{tabular}{c|c|c|}
\hline \multicolumn{3}{|c|}{ CONTAGEM - VARJÃO } \\
\hline Local & Pedestres & Veículos \\
\hline Ponto 1 & 70 & 48 \\
\hline Ponto 2 & 26 & 15 \\
\hline Ponto 3 & 26 & 9 \\
\hline Ponto 4 & 15 & 12 \\
\hline Ponto 5 & 4 & 1 \\
\hline TOTAL & 141 & 85 \\
\hline
\end{tabular}

\subsection{Taguatinga}

\subsubsection{Mapa Axial}

Em Taguatinga, cuja malha é ortogonal, verifica-se haver um maior equilíbrio entre a integração das vias, ou seja, a hierarquia já não é muito bem definida. Significa 
afirmar que o potencial de movimento neste espaço é mais equilibrado, havendo pessoas utilizando os espaços quase que de maneira uniforme, embora seja verificado a presença de uma via em vermelho (Figura 3.2.1 A)

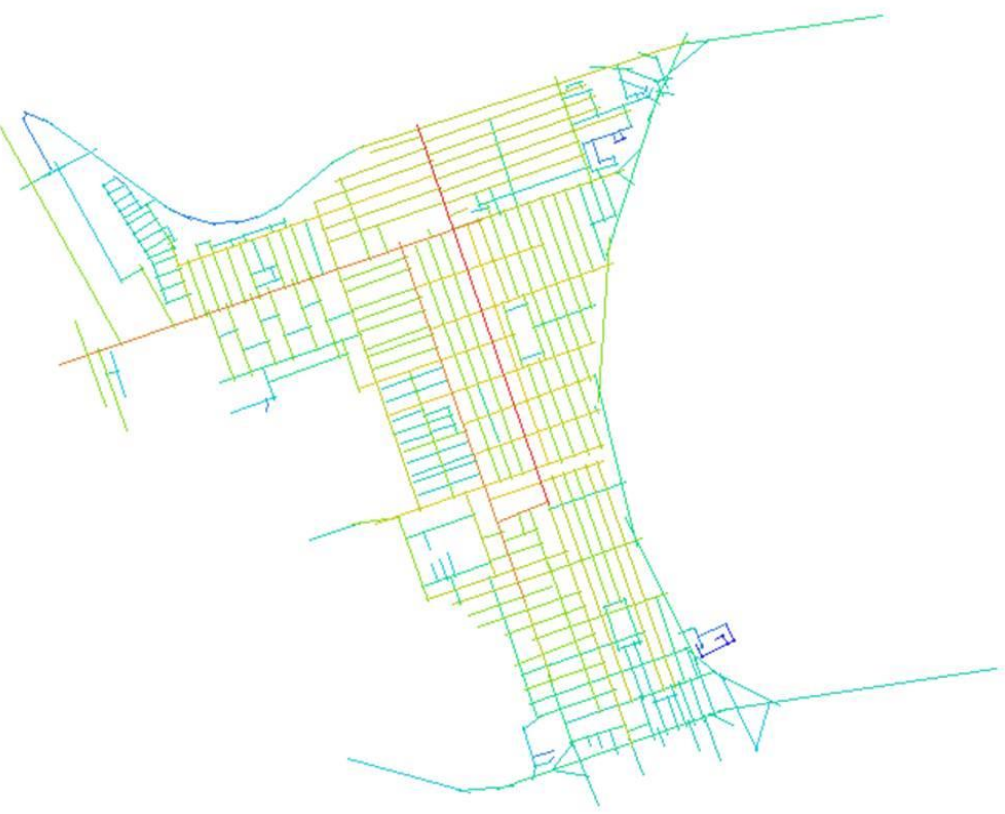

Figura 3.2.1 A - Mapa Axial de Taguatinga

\subsubsection{Uso do solo}

A avenida Comercial Norte de Taguatinga caracteriza-se por apresentar uma quantidade significativa de lojas de noivas, o que acaba, de certa maneira, por se tornar um aspecto negativo, haja vista apresentar uma especialização de atividade.

No entanto, há também muitas unidades de comércios e serviços de outras naturezas (Tabela 3.2.2) com pouquíssimos pontos cegos, aspectos essenciais para promover movimento, como ressaltado por Jacobs (2000), sendo bastante semelhante ao Varjão

Verificou-se também que a presença das residências na Av. Comercial é bem pequena e vai aumentando a medida que se afasta desta, ou seja, na via de transição, onde estão as fachadas 5 e 8 (Figura 2.2.2.D e Tabela 3.2.2) há maior mistura de usos comerciais e residenciais, e as fachadas 6 e 7 há presença marcante de residências. 
Tabela 3.2.2 - Uso do solo

\begin{tabular}{|c|c|c|}
\hline \multicolumn{3}{|c|}{ LEVANTAMENTO DE USO DE SOLO - TAGUATINGA } \\
\hline Fachada 1 & Fachada 4 & Fachada 6 \\
\hline Visara & Riachuello & Doce Docer Café Bistrô \\
\hline Louise Noivas e Festas & Loja $\mathrm{p} /$ alugar & 3 Residências \\
\hline Monatti Calçados & Drogafuji & Clínica de Estética Nova \\
\hline Salas piso superior & Sala de Advocacia - pav. sup. & Imagem \\
\hline Damyller & Romanel & 10 Residências \\
\hline Explosão Calçados & Terno \& Cia & DPIS Associados Advocacia \\
\hline Fachada 2 & Farmácias FTB & 4 Residências \\
\hline Loja fechada & Vitória Bijuterias & Fachada 7 \\
\hline Loja fechada & Colchões Ortobom & 20 Residências \\
\hline Cats moda jovem & Show Colchões & Fachada 8 \\
\hline Loja $\mathrm{p} /$ alugar & Fantine Self Shoes & Drogaria Salute Vida \\
\hline Couro Flex & Academia dança Corpusempar & Bob Pizza Quadrada \\
\hline Planeta do Bebê & Agittus Calçados & Cida Centro de Beleza \\
\hline Lara Calçados & ${ }^{*}$ Carrinho de Churros do tio & Sinalize Comunicação Prática \\
\hline Lojas Everest & $\begin{array}{c}\text { Fachada } 5 \\
\end{array}$ & impressão Digital \\
\hline Fachada 3 & Agittus Calçados & Edifício Residencial Beira Mar \\
\hline Vertical Jeans & Loja $\mathrm{p} /$ alugar & imóveis (construção) - lote 3 \\
\hline Loja p/ alugar & Michelle Joias & Edifício Residencial (constr.) \\
\hline Michelle Joias & Valentim Woman & Magazine da Economia \\
\hline Valentim Woman & Tesoura de Ouro & \\
\hline Tesoura de Ouro & Consciente: palestras, & \\
\hline Consciente: palestras, cursos e & cursos e treinamentos & \\
\hline treinamentos & Edifício Jk Taguatinga & \\
\hline Edifício Jk Taguatinga & Bela Pele - Perfumaria em & \\
\hline Bela Pele - Perfumaria em & móveis p/ salão & \\
\hline móveis $\mathrm{p} /$ salão & Galeria andar inferior - lojas & \\
\hline Galeria andar inferior - lojas & diversas & \\
\hline diversas & Unique Multimarcas & \\
\hline Unique Multimarcas & Rei dos Relógios & \\
\hline Rei dos Relógios & Leandra Bijuterias e Acessórios & \\
\hline Leandra Bijuterias e Acessórios & Loja p/ alugar & \\
\hline Loja $\mathrm{p} /$ alugar & & \\
\hline
\end{tabular}




\begin{tabular}{|c|c|c|}
\hline \multicolumn{3}{|c|}{ CONTINUAÇÃO: LEVANTAMENTO DE USO DE SOLO - TAGUATINGA } \\
\hline Fachada 9 & Fachada 10 & Fachada 11 \\
\hline Bradesco & Loja p/ alugar & Street Way Nutrição Esportiva \\
\hline Loja fechada & Terreno vazio & Drogaria Família \\
\hline Cãonia Petshop & Terreno vazio & Alicerce Imobiliária \\
\hline Portal Turismo & Priori Odonto & e Construções \\
\hline MUD Instituto de & Clínica Odontológica & Cheyre Noivas, Noivos, \\
\hline Música & de Taguatinga & Festas e Dubutantes \\
\hline Centro de Estética e & Mônica Policlínica & Espaço Silvana Carvalho - \\
\hline Salão de Beleza Lindona & High Tie Tecnologia & Noivas e Festas \\
\hline Palazzo Colchões - pav. sup. & que se vê & Lúcia Maia Noivas e Festas \\
\hline Kasa dos Colchões & Garagem da Radiograph & Isabella Bragança Noivas, \\
\hline Radiograph Clínica & Clínica de Imagem & Noivos e Festas \\
\hline de Imagem & Delicada Noiva & Fogo de Lenha \\
\hline Casa do Cawboy & Córdoba Ortodontia & Noiva Moderna \\
\hline \multirow[t]{15}{*}{ Santander } & Belle Noivas \& Noivos & La Fiesta Noiva \\
\hline & Loja $\mathrm{p} /$ alugar & Loja $\mathrm{p} /$ alugar \\
\hline & Salas piso superior & Apartamentos $\mathrm{p} /$ alugar - pav. \\
\hline & Edifício em construção & superior \\
\hline & Vitalle Farmácia de & Palácio Ágape Salões p/ \\
\hline & Manipulação & Festa, Buffet, Decoração \\
\hline & Puro Pano & Sonho Meu \\
\hline & Vitalle - pavimento superior & Diana Moura Esposa \\
\hline & Paspatur Convites e Caixas & Noivas e Damas \\
\hline & - pav. superior & Casarão das Noivas \\
\hline & Implantes, Próteses, Ortodontia & IPEM Treinamentos e Cursos- \\
\hline & pavimento superior & pav. térreo e superior \\
\hline & Residência & \\
\hline & CIMED Centro Integrado & \\
\hline & de Medicina & \\
\hline
\end{tabular}

\subsubsection{Número de portas}

De todo o perímetro estudado, abrangendo as 11 fachadas mostradas na Figura 2.2.2.D, nota-se que 8 delas se enquadram na classificação "ativa" de Gehl (2010) e 3 seguem com o título de "convidativas", semelhante ao que ocorre com o Varjão.

As fachadas 6 e 7 em muito excederam esse número, com 44 portas cada uma, por corresponderem a mais que o dobro do comprimento, cada uma com $220 \mathrm{~m}$. E, ainda que dividindo esse valor pela metade, teríamos 22 portas a cada $110 \mathrm{~m}$. O mais interessante é que tal quantidade além de superior às 20 portas de Gehl (sendo classificado como ativo), é esta também uma zona majoritariamente residencial. Contudo, havendo comércios intercalando as casas. Ou seja, não há uma setorização radical de funções conforme ocorre em malhas modernistas, o que permite maior fluxo 
de veículos e pedestres no local, sendo os olhos da rua (Jacobs, 2000) e proporcionam maior segurança aos espaços públicos.

Tabela 3.2.3 - Número de portas
\begin{tabular}{|c|c|}
\hline \multicolumn{2}{|c|}{$\begin{array}{c}\text { CONTAGEM No DE PORTAS - } \\
\text { TAGUATINGA }\end{array}$} \\
\hline Local & Quantidade \\
\hline Fachada 1 & 12 \\
\hline Fachada 2 & 12 \\
\hline Fachada 3 & 18 \\
\hline Fachada 4 & 18 \\
\hline Fachada 5 & 17 \\
\hline Fachada 6 & 44 \\
\hline Fachada 7 & 44 \\
\hline Fachada 8 & 11 \\
\hline Fachada 9 & 16 \\
\hline Fachada 10 & 27 \\
\hline Fachada 11 11 & 37 \\
\hline TOTAL & 256 \\
\hline
\end{tabular}

\subsubsection{Contagem de pedestres e veículos}

Os pontos 1 a 4 e 9 a 11 estão localizados na avenida comercial, verificou-se haver maior movimento (Tabela 3.2.4), sendo a passagem dos ônibus e, portanto, por onde naturalmente transitam mais indivíduos.

Tabela 3.2.4 - Número de portas

\begin{tabular}{|c|c|c|}
\hline \multicolumn{3}{|c|}{ CONTAGEM - TAGUATINGA } \\
\hline Local & Pedestres & Veículos \\
\hline Ponto 1 & 11 & 33 \\
\hline Ponto 2 & 16 & 25 \\
\hline Ponto 3 & 14 & 17 \\
\hline Ponto 4 & 10 & 18 \\
\hline Ponto 5 & 7 & 1 \\
\hline Ponto 6 & 4 & 5 \\
\hline Ponto 7 & 2 & 3 \\
\hline Ponto 8 & 10 & 31 \\
\hline Ponto 9 & 8 & 30 \\
\hline Ponto 10 & 18 & 35 \\
\hline Ponto 11 & 6 & 27 \\
\hline TOTAL & 106 & 225 \\
\hline
\end{tabular}


Já os pontos 5 a 8 correspondem à avenida perpendicular, que mescla residências e comércios, e onde já há alguns poucos pontos cegos, a quantidade de pessoas foi bem inferior (Tabela 3.2.4), tal como ocorreu com o Varjão.

\subsection{Plano Piloto}

\subsubsection{Mapa Axial}

Conforme alguns autores (Hillier e Hanson, 1984; Holanda, 2002; Medeiros, 2013; Barros, 2014) atestaram, as malhas modernistas são mais labirínticas, ou seja, mais segregadas que malhas consideradas tradicionais.

O mapa axial (Figura 3.3.1) mostra que as entrequadras são bem mais segregadas do entorno imediato do que ocorre no Varjão e em Taguatinga, ou seja, não estimulam o caminhar e sim o deslocamento veicular.

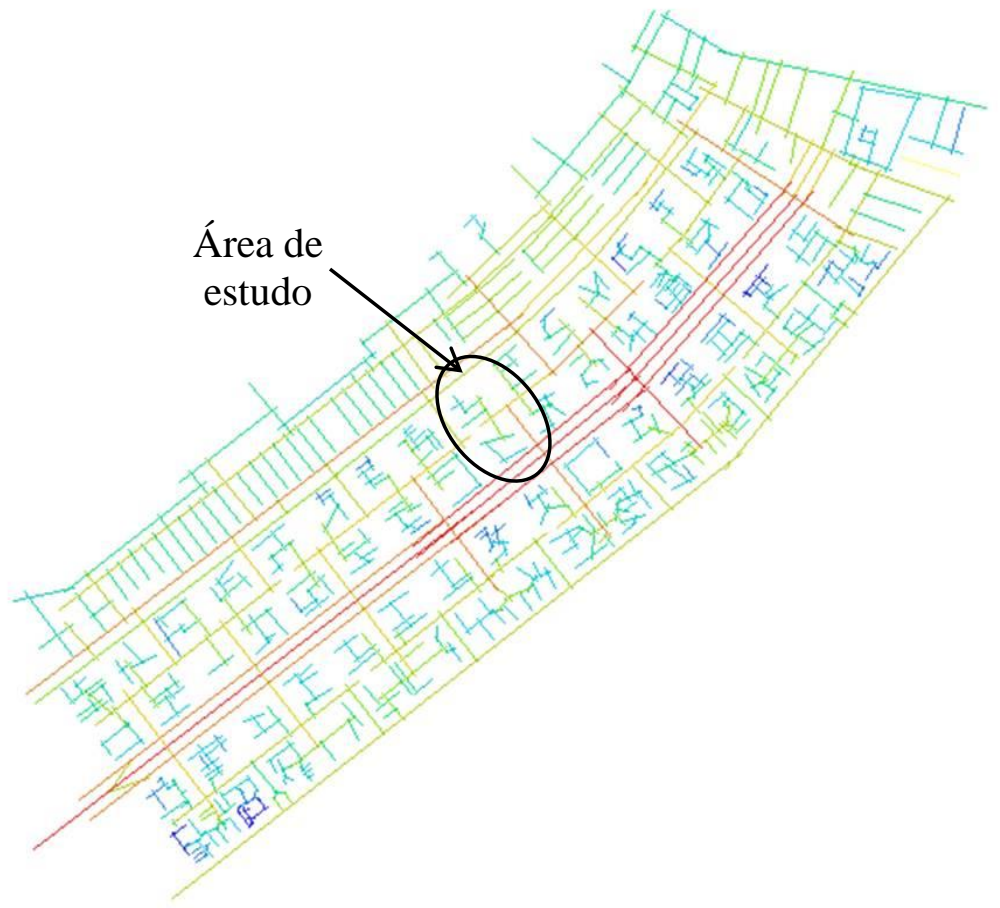

Figura 3.3.1 - Mapa Axial da Asa Sul 
O Plano Piloto de Brasília é um caso de estudo atípico, uma vez que o espaço segue os padrões da malha modernista, apesentando uma setorização rígida segregação entre a parte comercial e a residencial.

Na primeira, constatou-se que há certa diversidade de usos comerciais (Figuras 3.3.2 A e B e Tabela 3.3.2), apesar de não haver residências.

Tabela 3.3.2 - Uso do Solo

\begin{tabular}{ll}
\hline \multicolumn{1}{c}{ 108 SUL } \\
\multicolumn{1}{c|}{$\begin{array}{c}\text { LEVANTAMENTO } \\
\text { PLANO PILOTO }\end{array}$} \\
\hline $\begin{array}{l}\text { Ballet Norma Lílian Biavatty } \\
\text { Galeteria 108 sul }\end{array}$ & Churrascaria Estrela do Sul \\
\hline Di Petti Cães e Gatos & Loja fechada \\
\hline Drogaria Rosário & Devorê \\
\hline Califa Delícias Árabes & Correio Braziliense \\
\hline Gerson Maerde Hair \& Make & Ótica Santana \\
\hline Up & Caixa \\
\hline Panificadora Vitória & New York Bar e Restaurante \\
\hline Drogaria Avenida & Casa de carnes 107 sul \\
\hline Nação Hot Dog & Academia do Cabelo \\
\hline Loja fechada & Albert's \\
\hline Unha de Gata & Fábrica dos Bolos \\
\hline Mercearia Hitomi & Pastel Mix \\
\hline Dialma Dias Cabelereiros & Drogarias Pacheco \\
\hline Loja fechada & Casa das Meias \\
\hline Multicoisas & Imobiliária Remax Immobili \\
\hline Go Store Service Centro de & Pizzas Dom Bosco \\
\hline Soluções Especializada & Formiguinha Self Service \\
\hline Loterias & Bela Brasília \\
\hline Bolos do Flávio & Xique-Xique \\
\hline Godera Confeitaria e & \\
\hline Restaurante & \\
\hline Clinipet Núcleo de Clínica e & \\
\hline Cirurgia Especializada & \\
\hline Star Vidros & \\
\hline Loja fechada & \\
\hline Loja fechada & \\
\hline
\end{tabular}

Por outro lado, na zona residencial (Figuras 3.3.2 C e D e Tabela 3.3.2) não há comércio, havendo apenas aqueles de caráter informal (como chaveiro, ponto de táxi, vendedor de água de côco). Há edificações de uso institucional como, o Jardim de Infância 308 sul, a Escola Parque 308 Sul, a Escola Classe 308 Sul (ensino fundamental), e a Biblioteca Escolar e Comunitária da EQS 108/308 Professora Tatiana Eliza Nogueira. Em contrapartida há bastante área verde na quadra residencial, zonas 
de convívio e os edifícios são bem espaçados, mas ainda assim, os espaços não apresentam grande quantidade de pessoas, conforme apontam as contagens (Tabela 3.3.4A).

No entanto, cafés, restaurantes, farmácias, supermercados, bancos, salões de beleza, lojas de roupa e demais categorias que atraem um público maior de pessoas se concentram somente na quadra comercial (Tabela 3.3.2).

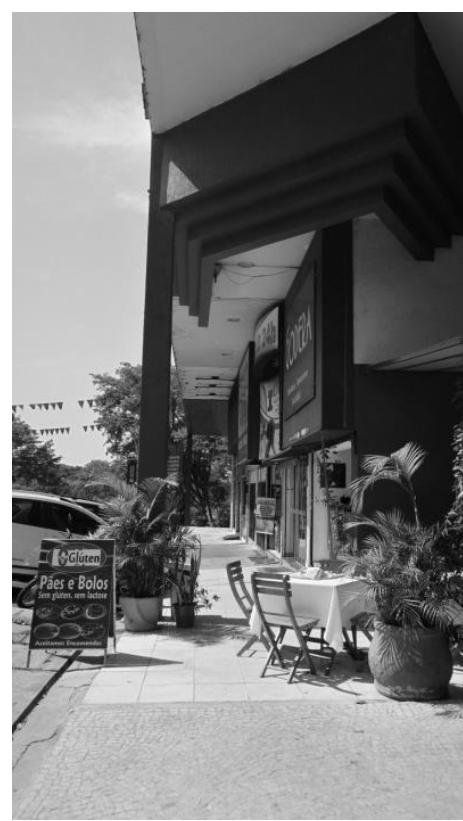

A

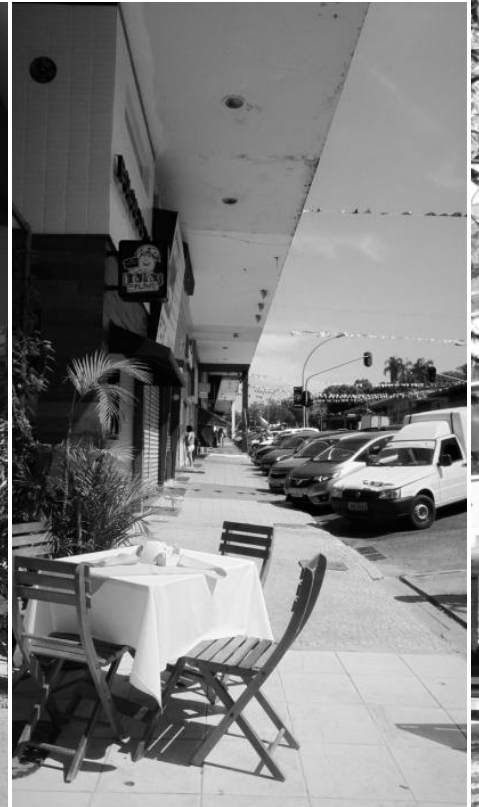

B

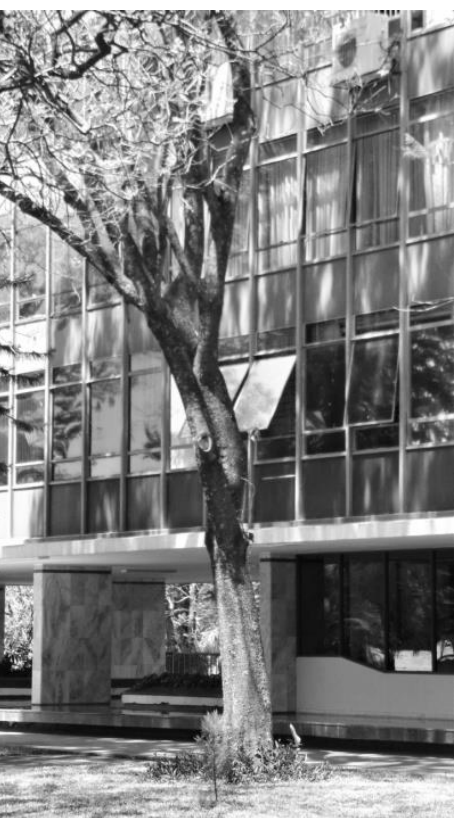

C

Figura 3.3.2.A (Comércio 108 Sul, visão sentido eixinho), Figura 3.3.2.B (Comércio 108 Sul, visão sentido Igrejinha), Figura 3.3.2.C (Visão do pilotis do bloco B da 308 Sul).

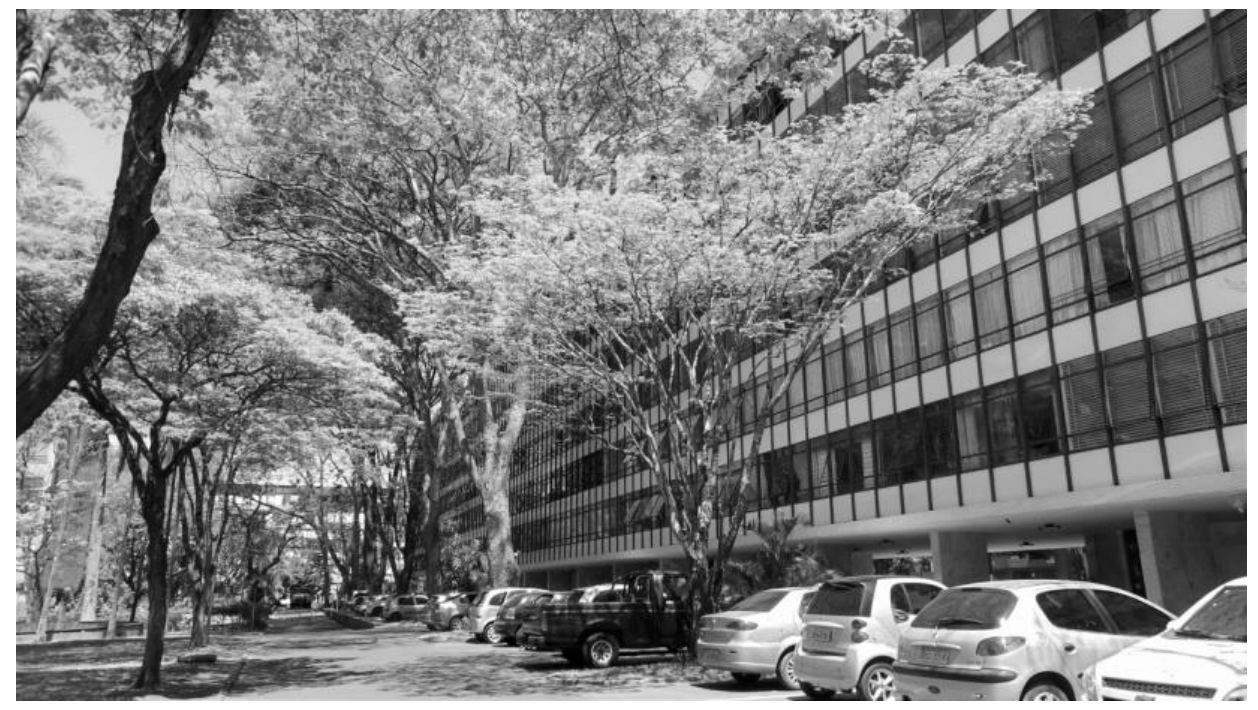


Figura 2.2.2.D - Visão interna da SQS 308.

\subsubsection{Número de portas}

Voltando à classificação quanto ao número de portas (Tabela 3.3.3), a 107 sul está na categoria "mista" e a 108 sul na categoria "convidativa", afinal a extensão das fachadas ocorre por $200 \mathrm{~m}$, no entanto, encontram-se algumas unidades cegas.

Por outro lado, na zona residencial o resultado encontrado classifica-se como "inativo", pois, retomando os preceitos de Gehl, há grandes unidades, poucas portas, pouquíssimas variações visíveis de função, unidades passivas e cegas, fachadas uniformes, faltam detalhes para se ver, o que desconvida o movimento pedonal na área.

Sob a perspectiva explorada por Gehl (2010), o espaço é classificado como "inativo" quando há 0 ou 1 porta, exceto pela fachada $A$, sendo a fachada de entrada, as demais não têm nenhuma porta voltada para a calçada externa da SQS 308.

No entanto, cabe aqui ressaltar que essas entradas existem, mas estão protegidas por outras paredes e/ou viradas para outros pontos de acesso em cada bloco residencial, mas mesmo assim são poucas portas por metragem, o que mostra o pouco estímulo de uso ao espaço.

Tabela 3.3.3 - Número de portas

\begin{tabular}{|c|c|c|}
\hline \multicolumn{3}{|c|}{ CONTAGEM № DE PORTAS - PLANO PILOTO } \\
\hline Tipologia de uso & Local & Quantidade \\
\hline \multirow{4}{*}{ Residencial } & Fachada A & 14 \\
\hline & Fachada B & 0 \\
\hline & Fachada C & 0 \\
\hline & Fachada D & 0 \\
\hline \multirow{2}{*}{ Comercial } & 107 sul & 19 \\
\hline & 108 sul & 25 \\
\hline TOTAL & & 58 \\
\hline
\end{tabular}

\subsubsection{Contagem de pedestres e veículos}

A pequena quantidade de portas (Gehl, 2010), a falta de atrativos e de usos principais combinados (Jacobs, 2000) associados a outros fatores como o perfil da vida 
urbana atual, fazem com que haja baixa movimentação de pessoas. E, assim, mesmo um espaço planejado, bem cuidado, arejado e arborizado fica prejudicado em relação à sua vivacidade urbana.

Verifica-se que os únicos pontos onde houve uma contagem significativa de pedestres (5, 6, 8, 14, 15, 23, 29 e 30 - Figura 2.2.2.H e Tabela 3.3.4) coincidem com as esquinas, ou seja, conforme cita Jacobs (2000) como sendo o espaço de maior probabilidade de haver encontros.

Tabela 3.3.4 - Contagem de Pedestres e Veículos

\begin{tabular}{|c|c|c|}
\hline \multicolumn{3}{|c|}{ CONTAGEM - PLANO } \\
PILOTO (107 e 108 Sul) \\
\hline Local & Pedestres & Veículos \\
\hline Ponto 1 & 2 & 41 \\
\hline Ponto 2 & 0 & 23 \\
\hline Ponto 3 & 0 & 26 \\
\hline Ponto 4 & 0 & 22 \\
\hline Ponto 5 & 0 & 23 \\
\hline Ponto 6 & 4 & 35 \\
\hline TOTAL & 6 & 170 \\
\hline
\end{tabular}




\begin{tabular}{|c|c|c|c|c|c|c|c|c|c|}
\hline \multicolumn{10}{|c|}{$\begin{array}{c}\text { CONT AGEM DE PEDESTRES - PLANO } \\
\text { PILOTO (SQS 308) }\end{array}$} \\
\hline $\begin{array}{l}\text { Pontos de } \\
\text { contagem }\end{array}$ & A & B & C & D & $E$ & $\mathbf{F}$ & $\mathbf{G}$ & $\mathbf{H}$ & TOTAL \\
\hline 1 & 4 & 4 & 2 & - & - & - & - & - & 10 \\
\hline 2 & 4 & 3 & 4 & 1 & - & - & - & - & 12 \\
\hline 3 & 5 & 1 & 6 & 2 & - & - & - & - & 14 \\
\hline 4 & 4 & 0 & 5 & 1 & - & - & - & - & 10 \\
\hline 5 & 7 & 7 & 0 & - & - & - & - & - & 14 \\
\hline 6 & 6 & 4 & 0 & 4 & 0 & 4 & - & - & 18 \\
\hline 7 & 3 & 4 & 2 & - & - & - & - & - & 9 \\
\hline 8 & 5 & 3 & 0 & 7 & - & - & - & - & 15 \\
\hline 9 & 0 & 4 & 0 & 4 & - & - & - & - & 8 \\
\hline 10 & 1 & 2 & 1 & 2 & - & - & - & - & 6 \\
\hline 11 & 2 & 2 & 1 & 3 & - & - & - & - & 8 \\
\hline 12 & 0 & 1 & 2 & 3 & - & - & - & - & 6 \\
\hline 13 & 3 & 6 & 1 & 4 & - & - & - & - & 14 \\
\hline 14 & 5 & 4 & 1 & 6 & 8 & - & - & - & 24 \\
\hline 15 & 3 & 2 & 2 & 1 & 4 & - & - & - & 12 \\
\hline 16 & 2 & 0 & 2 & - & - & - & - & - & 4 \\
\hline 17 & 0 & 0 & 0 & - & - & - & - & - & 0 \\
\hline 18 & 0 & 0 & 0 & - & - & - & - & - & 0 \\
\hline 19 & 1 & 1 & 1 & 1 & - & - & - & - & 4 \\
\hline 20 & 1 & 0 & 1 & - & - & - & - & - & 2 \\
\hline 21 & 2 & 1 & 3 & 2 & - & - & - & - & 8 \\
\hline 22 & 2 & 3 & 0 & 2 & - & - & - & - & 7 \\
\hline 23 & 5 & 4 & 5 & - & - & - & - & - & 14 \\
\hline 24 & 0 & 0 & 0 & 2 & 1 & 0 & 1 & 0 & 4 \\
\hline 25 & 1 & 4 & 0 & 0 & 0 & 3 & - & - & 8 \\
\hline 26 & 2 & 2 & 0 & 0 & - & - & - & - & 4 \\
\hline 27 & 4 & 0 & 2 & 2 & 0 & 0 & - & - & 8 \\
\hline 28 & 2 & 2 & 0 & 0 & 2 & - & - & - & 6 \\
\hline 29 & 3 & 2 & 3 & 3 & 5 & - & - & - & 16 \\
\hline 30 & 5 & 0 & 5 & 0 & - & - & - & - & 10 \\
\hline 31 & 2 & 2 & 2 & 2 & - & - & - & - & 8 \\
\hline \multicolumn{9}{|l|}{ TOTAL } & 283 \\
\hline
\end{tabular}




\section{CONSIDERAÇÕES FINAIS}

Conforme apresentado, no tocante aos mapas axiais, observa-se o fato das duas primeiras cidades - Varjão e Taguatinga - caracterizarem-se como morfologias "tradicionais", suas vias concentram a maior diversidade, número de portas e de pessoas, o que apresenta maior integração (em vermelho). Na Asa Sul, por outro lado, o fato de haver uma rígida separação de usos - uso residencial estar separado do comercial - faz com que haja menor número de portas, principalmente, na área residencial, bem como, um menor número de pessoas (Jacobs, 2001), e, portanto, vias com menor integração.

De acordo com o levantamento de usos realizado, verificou-se que no Varjão e em Taguatinga há uma quantidade e diversidade de uso bastante rica, o que não acontece na Asa Sul, uma vez que nesta a setorização é bastante rígida, ou seja, as residências situam-se com certa distância dos comércios/serviços. Tal separação provoca maiores deslocamentos entre os setores e, normalmente, realizados com carros, fomentando a ausência de vida nos espaços, ou seja, menor número de pessoas nos espaços.

No que tange o número de portas, observou-se o mesmo padrão, no Varjão e em Taguatinga este número é bem superior que na Asa Sul. Isto está diretamente relacionado com a diversidade de usos (Jacobs, 2001), pois Gehl (2010) acredita que quanto maior o número de empreendimentos - pequenos empreendimentos - maior o número de portas, maior o detalhamento das fachadas e, portanto, mais atrativo para as pessoas.

Aliado ao estudo realizado por Barros (2014), pode-se constatar que independente do continente se esteja, a morfologia dos espaços interfere de forma bastante semelhante os deslocamentos das pessoas. Em outras palavras, espaços mais tradicionais estimulam o caminhar a $5 \mathrm{~km} / \mathrm{h}$ (Gehl, 2010), possibilitando haver maior convívio entre as pessoas e, portanto, mais vida nos espaços. Diferentemente, do que ocorre em espaços modernistas, em que o estímulo é dado aos deslocamentos motorizados, uma vez que as atividades estão distantes, o que fomenta espaços mortes, com poucas ou nenhuma vida urbana. 


\section{REFERÊNCIAS}

AMÂNCIO, M. A. (2006) Relacionamento entre a forma urbana e as viagens a pé. Dissertação de Mestrado. Programa de Pós Graduação em Engenharia Urbana. Universidade Federal de São Carlos, São Carlos.

ANDRADE, S. (2015) ESTUDO DE CASO: Morfologia urbana e uso do solo como fomentadores de deslocamentos motorizados e não motorizados. Brasília: Trabalho de Conclusão de Curso. Centro Universitário de Brasília - UniCEUB.

BARROS, A. P. (2014) Diz-me como andas que te direi onde estás: a inserção da visão relacional na análise da mobilidade urbana para o pedestre. Tese de doutorado em regime de Cotutela na área de Transportes pelas Universidade de Brasília e de Lisboa. Brasília/Lisboa. pp. 408.

BERTALANFFY, L. (2012) Teoria Geral dos Sistemas. 6aㅡ Edição. Petrópolis: Editora Vozes.

CAPRA, F. (2003) A teia da vida: uma nova compreensão científica dos sistemas vivos. 8를ição. São Paulo: Cultrix.

COSTA, M. S. (2008) Um índice de mobilidade urbana sustentável. Tese de Doutorado. Escola de Engenharia de São Carlos. Universidade de São Paulo, São Carlos. 248p.

DERRIDA, J. (1971) A escritura da diferença. (Coleção Debates, 49). Perspectiva: São Paulo.

FOUCAULT, M. (1971) Sobre a Arqueologia das Ciências. In: Foucault, M. et alli. Estruturalismo e teoria da linguagem. (Coleção Epistemologia e Pensamento Contemporâneo, 1). Vozes: Petrópolis.

GEHL, J. (2010) Cities for people. Washington D.C.: Island Press.

HILLIER, B. (1996) Space is the machine. London: Cambridge University Press.

HILLIER (2005) Between social physics and phenomenology: explorations towards an urban synthesis. In: 5th International Space Syntax Symposium, Delft - Holanda. Proceedings» Delft: Section of Urban Renewal and Management/Faculty of Architecture/TU Delft, 1, pp. 3-23.

HILLIER, B. and HANSON, J. (1984). The Social Logic of Space. London: Cambridge University Press.

HILLIER, B. and HANSON, J. (1997) The reasoning art: or, the need for an analytical theory of architecture. In: 1st linternational Space Syntax Symposium, Londres - 
Inglaterra. Proceedings... Londres: Space Syntax Laboratory/The Bartlett School of Graduate Studies/University College London. 1, pp. 01.1-01.05.

HILLIER, B.; PENN, A.; HANSON, J; GRAJEWSKi, T.; XU, J. (1993) Natural movement: or, configuration and attraction in urban pedestrian movement. Environment and Planning B, London: Pion Publication, 20, 1,pp. 29-66.

HOLANDA, F. (2002) O espaço de exceção. Brasília: EdUnB.

JACOBS, J. (2000) Morte e vida de grandes cidades. São Paulo: Martins Fontes

LEFEBVRE, H. (1999) A revolução urbana. Humanitas. Belo Horizonte: Editora UFMG.

MEDEIROS, V. A. S. (2013) Urbis Brasiliae: o labirinto das cidades brasileiras. Brasília: EdUnB.

MORIN, E. (2005) Ciência com consciência. 8ª Edição. Rio de Janeiro: Bertrand Brasil.

NICOLESCU, B. (1999) O manifesto da transdisciplinaridade. São Paulo: Triom. 